Provided for non-commercial research and education use. Not for reproduction, distribution or commercial use.

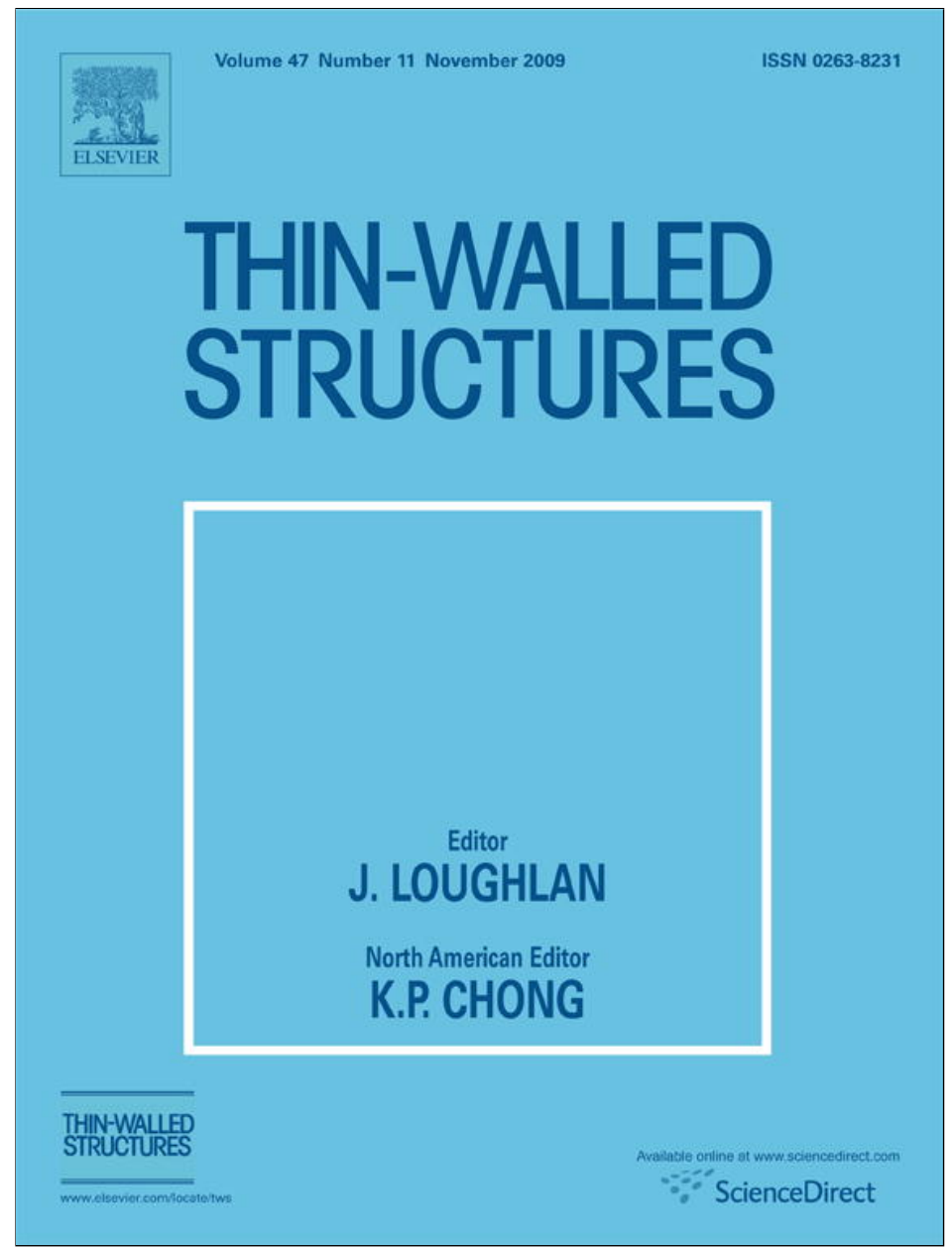

This article appeared in a journal published by Elsevier. The attached copy is furnished to the author for internal non-commercial research and education use, including for instruction at the authors institution and sharing with colleagues.

Other uses, including reproduction and distribution, or selling or licensing copies, or posting to personal, institutional or third party websites are prohibited.

In most cases authors are permitted to post their version of the article (e.g. in Word or Tex form) to their personal website or institutional repository. Authors requiring further information regarding Elsevier's archiving and manuscript policies are encouraged to visit:

http://www.elsevier.com/copyright 


\title{
Sensitivity analysis on the elastic buckling and ultimate strength of continuous stiffened aluminium plates under combined in-plane compression and lateral pressure
}

\author{
Mohammad Reza Khedmati $^{\mathrm{a}, *}$, Mohammad Reza Zareei ${ }^{\mathrm{b}}$, Philippe Rigo ${ }^{\mathrm{c}}$ \\ a Faculty of Marine Technology, Amirkabir University of Technology, Tehran 15914, Iran \\ ${ }^{\mathrm{b}}$ Shipbuilding Group, Faculty of Engineering, Chabahar Maritime University, Chabahar 99717-56499, Iran \\ ' University of Liège, ANAST, Chemin des Chevreuils 1 (B52/3), 4000 Liège, Belgium
}

\section{A R T I C L E I N F O}

\section{Article history:}

Received 11 March 2009

Received in revised form

13 April 2009

Accepted 20 April 2009

Available online 26 May 2009

Keywords:

Buckling load

Ultimate strength

Post-buckling behaviour

Continuous stiffened aluminium panels

Axial compression

Lateral pressure

Heat-affected zone

Finite element method (FEM)

\begin{abstract}
A B S T R A C T
In this paper, the results of an investigation into the post-buckling behaviour of high-strength aluminium alloy stiffened plates subjected to combined axial compression load and different magnitudes of lateral pressure using non-linear finite element approach is presented. Both material and geometric non-linearities have been taken into account. The principal variables studied are the plate thickness, boundary conditions and the stiffener geometries beside the geometrical imperfection, the width of the welding heat-affected zone (HAZ) and welding residual stresses. The influence of these variables on the post-buckling behaviour and ultimate strength of such stiffened plates has been investigated in details.
\end{abstract}

(c) 2009 Elsevier Ltd. All rights reserved.

\section{Introduction}

Stiffened plates are used as main supporting members in many civil as well as marine structural applications. They typically consist of a plate with equally spaced stiffeners welded on one side, often with intermediate transverse stiffeners or bulkheads. The most common stiffener cross-sections are bulb, flat bar or $\mathrm{T}$ - and L-sections. Such structural arrangements are common for both steel and aluminium structures.

Aluminium panels have been used in a variety of marine structures, with applications such as hull and decks in high-speed boats and catamarans and superstructures for ships. Other applications are box-girder bridges, and walls and floors in offshore modules and containers. These panels are primarily required to resist axial compressive forces, even though transverse loads and in-plane shear forces may in general interact.

The ultimate strength design formulae available for steel plates cannot be directly applied to aluminium plates even though the corresponding material properties are properly accounted for. This is partly due to the fact that the constitutive stress-strain

\footnotetext{
* Corresponding author. Tel.: +98 2164543113 ; fax: +98 2166412495

E-mail address: khedmati@aut.ac.ir (M.R. Khedmati).
}

relationship of the aluminium alloys is different from that of structural steel. In the elastic-plastic range after the proportional limit as compared to structural steel, the strain hardening has a significant influence in the ultimate load behaviour of aluminium structures whereas in steel structures, the elastic-perfectly plastic material model is well adopted. Besides, the softening in the heataffected zone (HAZ) significantly affects the ultimate strength behaviour of aluminium structures, whereas its effect in steel structures is of very little importance.

The ultimate strength of stiffened steel plate panels has been the subject of many investigations, both experimentally [1-5] and numerically [6-10], with the most significant contributions in the field of ship structures and bridges. The literature on stiffened aluminium panels is more limited. Clarke [11] reports on buckling tests on an aluminium AA5083 plate with welded T-bar and flatbar stiffeners. His experimental programme comprised eight compression tests on panels with different plate and stiffener sizes, with buckling over two spans as the failure mode. The ultimate strength of stiffened aluminium AA6082-T6 plates under the axial compression was investigated by Aalberg et al. [12,13] using numerical and experimental methods. Kristensen and Moan [14] demonstrated numerically the effect of HAZ and residual stresses on the ultimate strength of rectangular aluminium plates (AA5083 and AA6082) under the bi-axial loading of plates. 


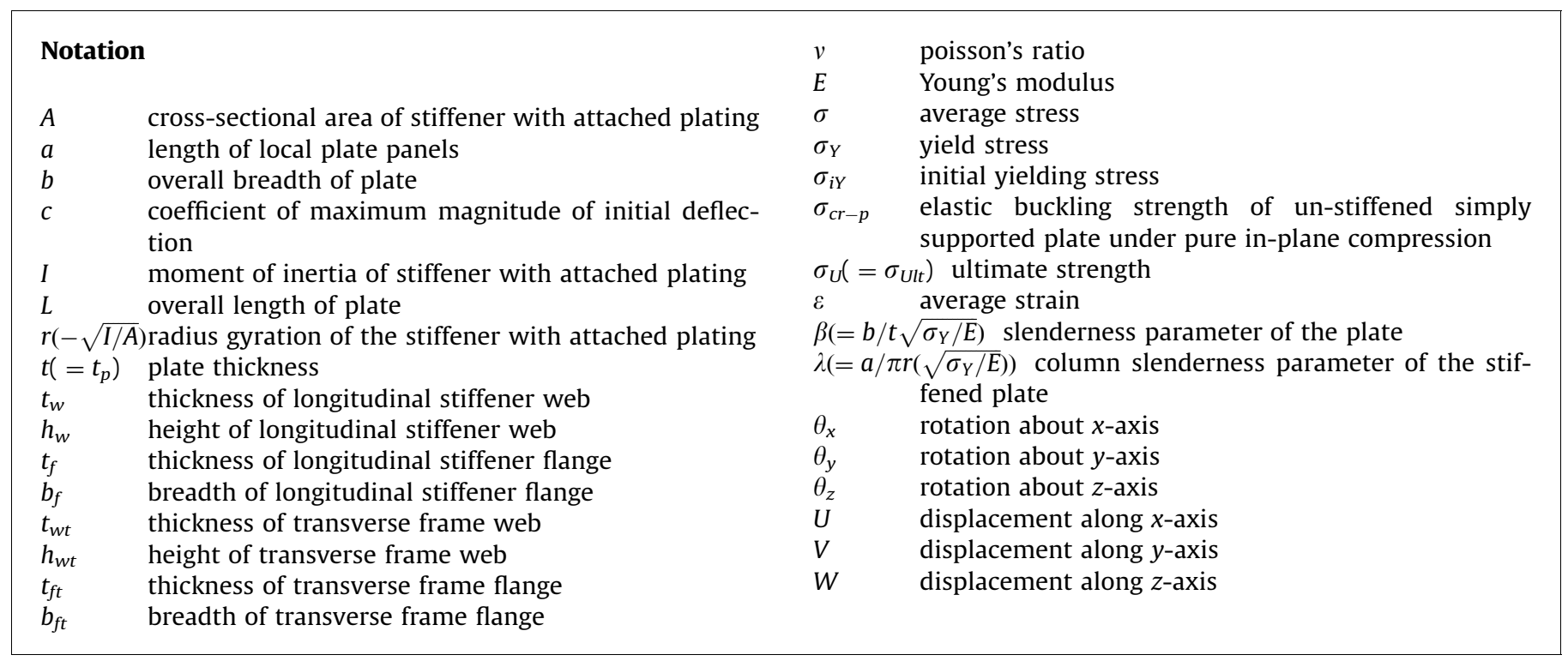

Some initial experimental and numerical simulations on torsional buckling of flat bars in aluminium panels have been also presented by Zha and Moan [15-17]. Hopperstad et al. [18] carried out a study with the objective of assessing the reliability of non-linear finite element analyses in predictions on ultimate strength of aluminium plates subjected to in-plane compression. Rigo et al. [19] made a numerical investigation to present reliable finite element models to study the behaviour of axially compressed stiffened aluminium panels (including extruded profiles).

Among most recent works, reference can be made to the work of Paik et al. [20] on the subject of ultimate limit state design of multi-hull ships made in aluminium. The impact of initial imperfections due to the fusion welding on the ultimate strength of stiffened aluminium plates was studied by Paik et al. [21] and Collette [22]. Paik et al. [21] defined the fabrication related initial imperfections of fusion-welded stiffened aluminium plate structures at the three levels. Also Paik et al. [23] derived empirical formulations for predicting ultimate strength of stiffened aluminium plates under axial compression. Future trends and research needs in aluminium structures were outlined by Sielski [24]. Mechanical collapse tests on stiffened aluminium structures for marine applications were performed by Paik et al. [25,26]. Most recently, Paik et al. studied buckling collapse testing of friction stir welded aluminium-stiffened plate structures [27].

In most of aforementioned studies, only the case of in-plane compression has been considered as applied loading condition of the stiffened plate panels. Post-buckling behaviour and strength of such stiffened panels under combined in-plane compression and lateral pressure have not been addressed yet to our knowledge.

In this paper, the post-buckling behaviour and ultimate strength characteristics of stiffened aluminium plates under combined axial compressive and lateral pressure loads are investigated using non-linear finite element method. Plate dimensions, stiffener type and stiffener dimensions are varied in a systematic manner in the analyses. In addition, average initial weld-induced deflection, welding residual stresses and also softening in heat-affected zone are considered throughout the investigation.

\section{Models for analysis}

\subsection{Structural arrangements and geometrical characteristics}

The geometrical characteristics of the analysed stiffened plates are given in Table 1 . Three types of models have been considered. In each type, three different shapes of stiffeners (flat, angle and tee) have been attached to the isotropic plate, Fig. 1. The stiffened plates of each type have the same moment of inertia. Types 1, 2 and 3 correspond, respectively, to weak, medium and heavy stiffeners.

Table 1

Geometrical characteristics of the aluminium-stiffened plates.

\begin{tabular}{|c|c|c|c|c|c|c|c|c|c|c|c|c|}
\hline \multirow[t]{2}{*}{ Type } & \multirow[t]{2}{*}{ Model } & \multirow[t]{2}{*}{ Shape } & \multicolumn{3}{|l|}{ Plate } & \multicolumn{4}{|c|}{ Longitudinal stiffener } & \multicolumn{3}{|c|}{ Stiffened Plate } \\
\hline & & & $a(\mathrm{~mm})$ & $b(\mathrm{~mm})$ & $t(\mathrm{~mm})$ & $t_{w}(\mathrm{~mm})$ & $h_{w}(\mathrm{~mm})$ & $t_{f}(\mathrm{~mm})$ & $b_{f}(\mathrm{~mm})$ & $I\left(\mathrm{~mm}^{4}\right)$ & $\beta$ & $\lambda$ \\
\hline \multirow[t]{3}{*}{ 1: Weak stiffener } & $\mathrm{F} 1$ & Flat & \multirow{3}{*}{900} & \multirow{3}{*}{300} & 7 & 5 & 53.5 & - & - & 226254 & 2.603 & 0.787 \\
\hline & L1 & Angle & & & 6 & 4 & 40 & 4 & 20 & 226380 & 3.037 & 0.790 \\
\hline & $\mathrm{T} 1$ & Tee & & & 6 & 4 & 40 & 4 & 20 & 226380 & 3.037 & 0.790 \\
\hline \multirow[t]{3}{*}{ 2: Medium stiffener } & $\mathrm{F} 2$ & Flat & \multirow{3}{*}{900} & \multirow{3}{*}{300} & 7 & 6 & 82.2 & - & - & 804521 & 2.603 & 0.426 \\
\hline & L2 & Angle & & & 6 & 5 & 60 & 5 & 30 & 803652 & 3.037 & 0.411 \\
\hline & $\mathrm{T} 2$ & Tee & & & 6 & 5 & 60 & 5 & 30 & 803652 & 3.037 & 0.411 \\
\hline \multirow[t]{3}{*}{ 3: Heavy stiffener } & F3 & Flat & \multirow{3}{*}{900} & \multirow{3}{*}{300} & 8 & 10 & 107.6 & - & - & 2503753 & 2.278 & 0.273 \\
\hline & L3 & Angle & & & 6 & 8 & 80 & 8 & 40 & 2505550 & 3.037 & 0.271 \\
\hline & Т3 & Tee & & & 6 & 8 & 80 & 8 & 40 & 2505550 & 3.037 & 0.271 \\
\hline
\end{tabular}



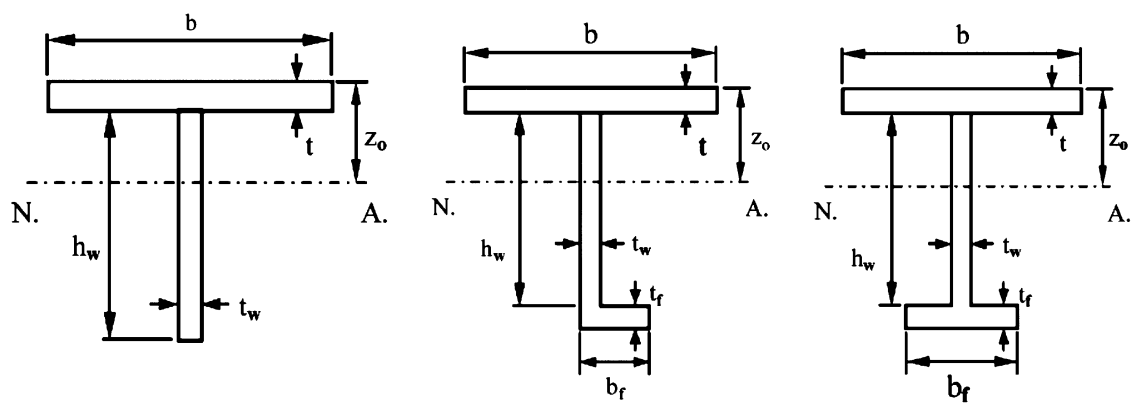

Fig. 1. Cross-sectional geometries of aluminium-stiffened plates [23].

a

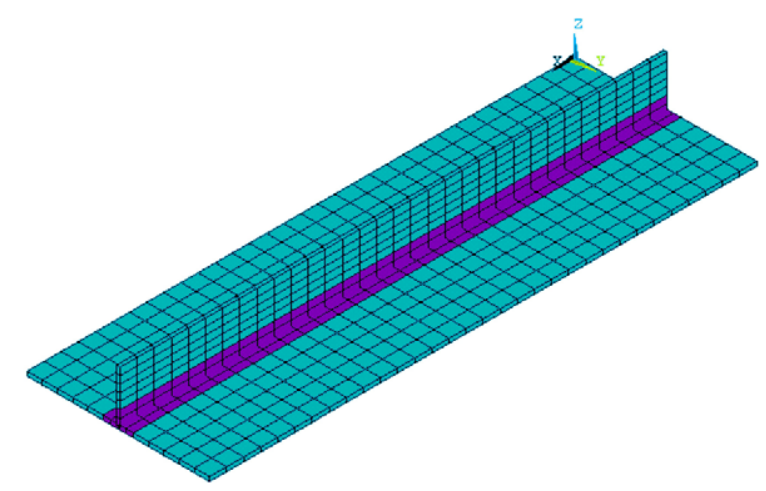

$\mathrm{b}$

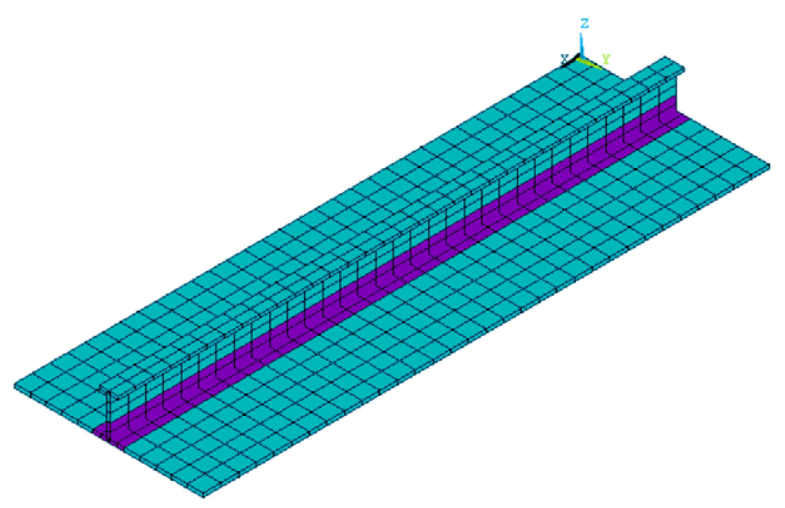

C

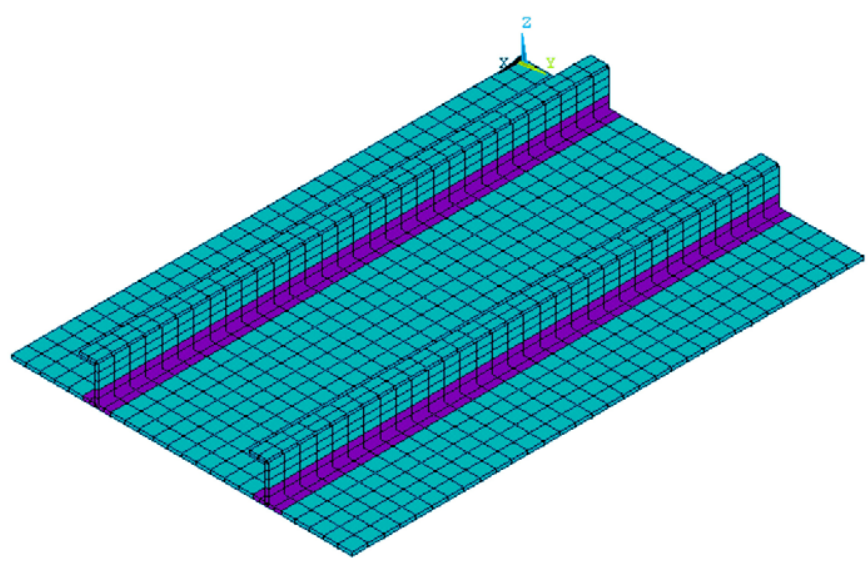

Fig. 2. Typical examples of the mesh models. (a) Flat-bar stiffened plate. (b) Teebar stiffened plate. (c) Angle-bar stiffened plate.

\subsection{Finite element code and adopted elements}

A non-linear elastic-plastic finite element analysis is the only method capable of simulating the succession of all buckling phenomena that occur during the quasi-static compression of a stiffened plate. To predict the ultimate strength of thin-walled structures, plate-shell elements are employed for both membrane and bending stiffness. In this analysis the mesh size must be fine enough to capture the long-wave-length buckling modes, such as torsional buckling, and also to account for the continuity of the plate through the transverse frames. Furthermore, the mesh needs to be fine enough to recognize the initial imperfections to make sure that buckling occurs and to avoid unduly stiff behaviour. The buckling/plastic collapse behaviour and ultimate strength of aluminium-stiffened plates are hereby assessed using ANSYS [28], in which both material and geometric non-linearities are taken into account.

Among the library of the available elements of the ANSYS FEM program, the four-node SHELL43 and eight-node SHELL181 elements are used for the mesh of the stiffened plate models, respectively, when neglecting and assuming welding residual stresses. In each case, 300 elements are used to model each local plate panel (the panel surrounded by successive longitudinal or transverse stiffeners), 6 to 7 and 5 to 6 elements are also considered, respectively, along web and flange stiffener. Fig. 2 shows typical examples of the stiffener mesh models.

\subsection{Mechanical properties of material}

The material properties were taken from the Aalberg experiments [13]. The Young modulus and the Poisson ratio of the material are $70.475 \mathrm{GPa}$ and 0.3 , respectively. The stress-strain relationship of the aluminium alloy is shown in Fig. 3(a). The breadth of HAZ is assumed to be $50 \mathrm{~mm}$ in the plate and $25 \mathrm{~mm}$ in the stiffener web, at the plate-stiffener junction, Fig. 3(b).

\subsection{Extent of the model, boundary and loading conditions}

As it was mentioned in the introduction, there are many research studies regarding the buckling and ultimate strength of plates. In most of these studies, an isolated plate between longitudinal stiffeners and transverse frames was considered assuming simply supported boundaries around the plate. However, when continuous plating is subjected to a high lateral pressure, the plate deflects in the same direction in all adjacent spans or bays. Therefore, for large lateral pressure the plate can be considered as clamped along the two long edges, when the longitudinal compression is applied. As a result, according to 


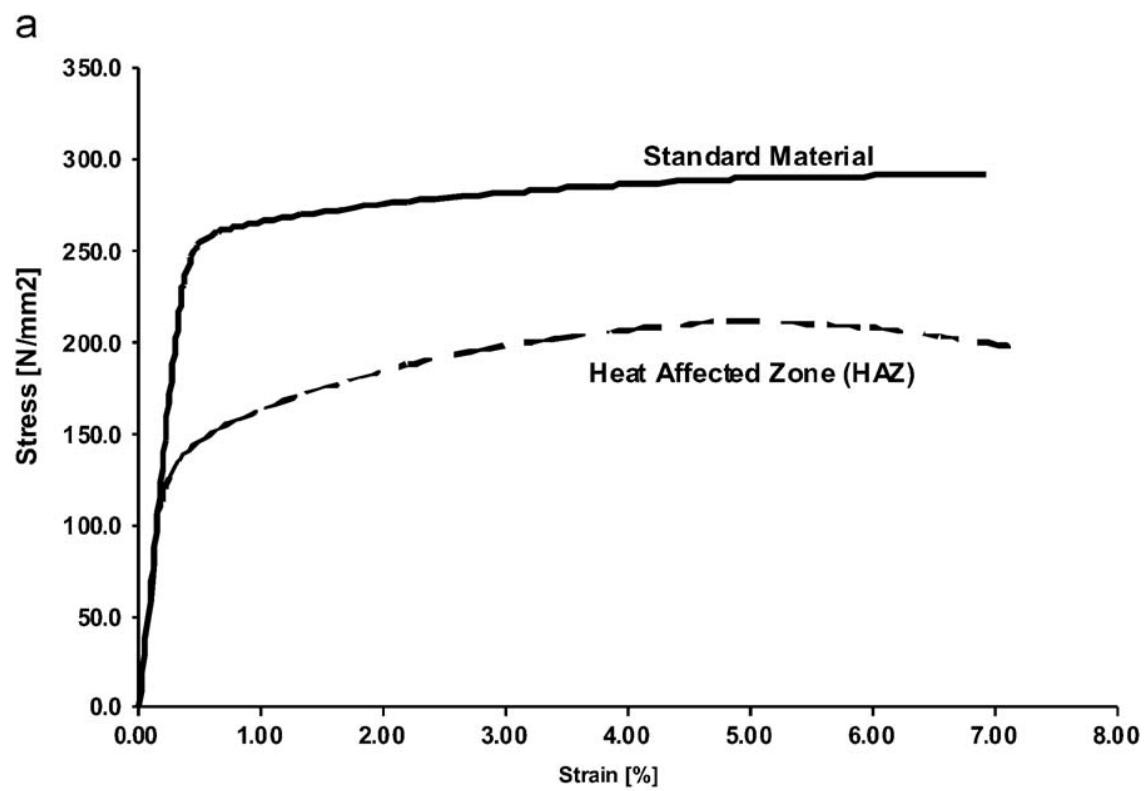

b

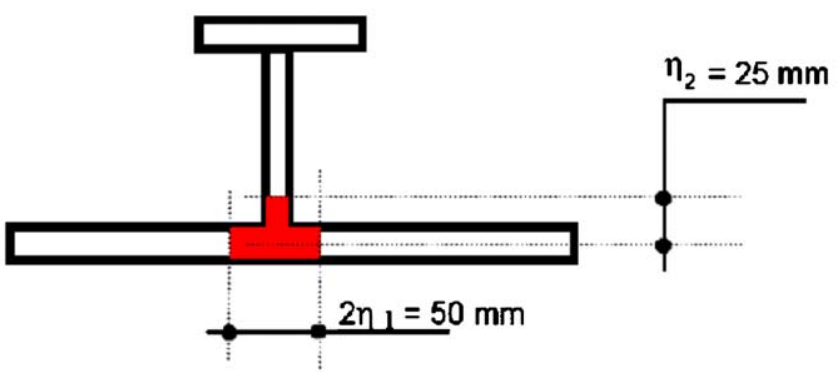

Fig. 3. Stress-strain behaviour of the material and exent of the HAZ. (a) Material stress-strain behaviour. (b) Extent of the heat-affected zone (HAZ) in both plate and stiffener.

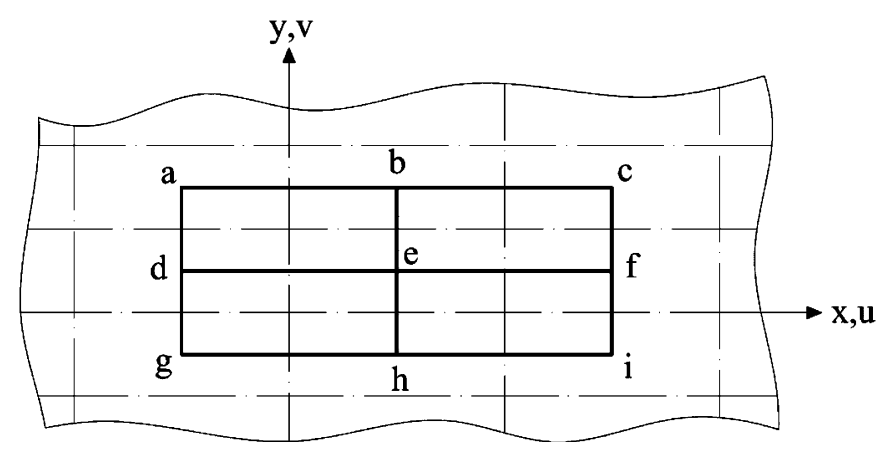

Fig. 4. Extent of the continuous stiffened plate models for analysis.

the numerical studies on continuous ship bottom plating under combined in-plane compression and lateral pressure [29,30], both elastic buckling strength and ultimate strength become larger than those for the simply supported isolated plates. Thus, continuous stiffened plate models are to be used in such analyses [31].

A double span-single stiffener (DS-SS) or in other words double span-single bay (DS-SB) model (acdf in Fig. 4) has been chosen for the analysis of buckling/plastic collapse behaviour of aluminiumstiffened plate with symmetrical stiffeners [29]. For the analysis of the stiffened plates with non-symmetrical stiffeners, a double span-double bay (DS-DB) or double span- double stiffener (DS-DS) model (acgi in Fig. 4) has been considered. The boundary conditions of the analysed plates are as follow:

- Periodically continuous conditions are imposed at the same $x$-coordinate along the longitudinal edges in the double stiffener model (i.e. along ac and gi). These conditions are defined as below:

$$
\begin{aligned}
u_{a b c} & =u_{g h i} \\
w_{a b c} & =w_{g h i} \\
\theta_{x-a b c} & =\theta_{x-g h i} \\
\theta_{y-a b c} & =\theta_{y-g h i} \\
\theta_{z-a b c} & =\theta_{z-g h i}
\end{aligned}
$$

- Symmetry conditions are imposed at the same $x$-coordinate along the longitudinal edges in the single stiffener model (i.e. along ac and df).

- Symmetry conditions are imposed at the same $y$-coordinate along the transverse edges in the double span model (i.e. along adg and beh).

- Although transverse frames are not modelled, the out-of-plane deformation of plate is restrained along its junction line with the transverse frame.

- To consider the plate continuity, in-plane movement of the plate edges in their perpendicular directions is assumed to be uniform.

After producing initial deflection in the stiffened plate, lateral pressure is applied first on it until assumed levels. Then, longitudinal compression in exerted on the stiffened plate. 


\subsection{Initial imperfections}

In order to simulate the complex pattern of initial deflection [19], lateral pressure was applied first on the stiffened plate model and a linear elastic finite element analysis was carried out. Such an analysis was repeated in a trial and error sequence of calculations until the deflection of plate reaches to the average value given by Eq. (2)

$W_{0 \max }=c \beta^{2} t$

The value of coefficient $c$ depends on the level of initial deflection. The maximum magnitude of initial deflection, $W_{0 \max }$, is usually taken from the work of Smith et al. [32]

$W_{0 \max }= \begin{cases}0.025 \beta^{2} t & \text { for slight level } \\ 0.1 \beta^{2} t & \text { for average level } \\ 0.3 \beta^{2} t & \text { for severe level }\end{cases}$

The average value of initial deflection in ship plating was also investigated and evaluated by Varghese [33] as

$W_{0 \max }=0.05 \beta^{2} t$

After satisfying this condition, the data information i.e the coordinates of nodal points, element coordinates and boundary conditions, were extracted and transferred to a new finite element mesh. The new model was used for a non-linear FEA analysis of the stiffened plate subjected to in-plane compression with variable lateral loads. The procedure generating initial deflection is shown schematically in Fig. 5. After this step, lateral pressure is applied until the assumed levels, before the application of inplane longitudinal compression load $[29,30]$.

In addition to the initial deflections in both plate and stiffener, material softening in the so-called heat-affected zone and also welding residual stresses is taken into account.

\subsection{Zha and Moan tests}

A total of 21 stiffened aluminium panels were tested by Zha and Moan [17]. The nominal geometrical dimensions of specimen are shown in Fig. 6. Two sets of test specimens were made by them, one based on aluminium AA5083-H116 and the other on AA6082-T6, respectively. Plate thickness, stiffener height and web thickness were varied in each set. End plates of each specimen were machined parallel to achieve uniform application of load. A test rig was designed as shown in Fig. 6.

The longitudinal edges of the specimens were free, while the stiffened panel was simply supported along the transverse boundaries. The test specimen was mounted in a vertical position. The axial compressive loading was applied at the upper end of the specimen through a rigid loading set, while the reaction force was carried by the lower end support set. Before testing, initial imperfections of the stiffened panels were measured. During the tests, the axial compressive load was applied by slowly imposing a displacement subsequently the deformation of the stiffened plate

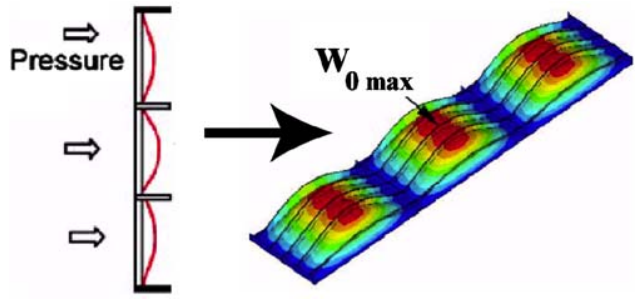

Fig. 5. Procedure to generate initial deflection.

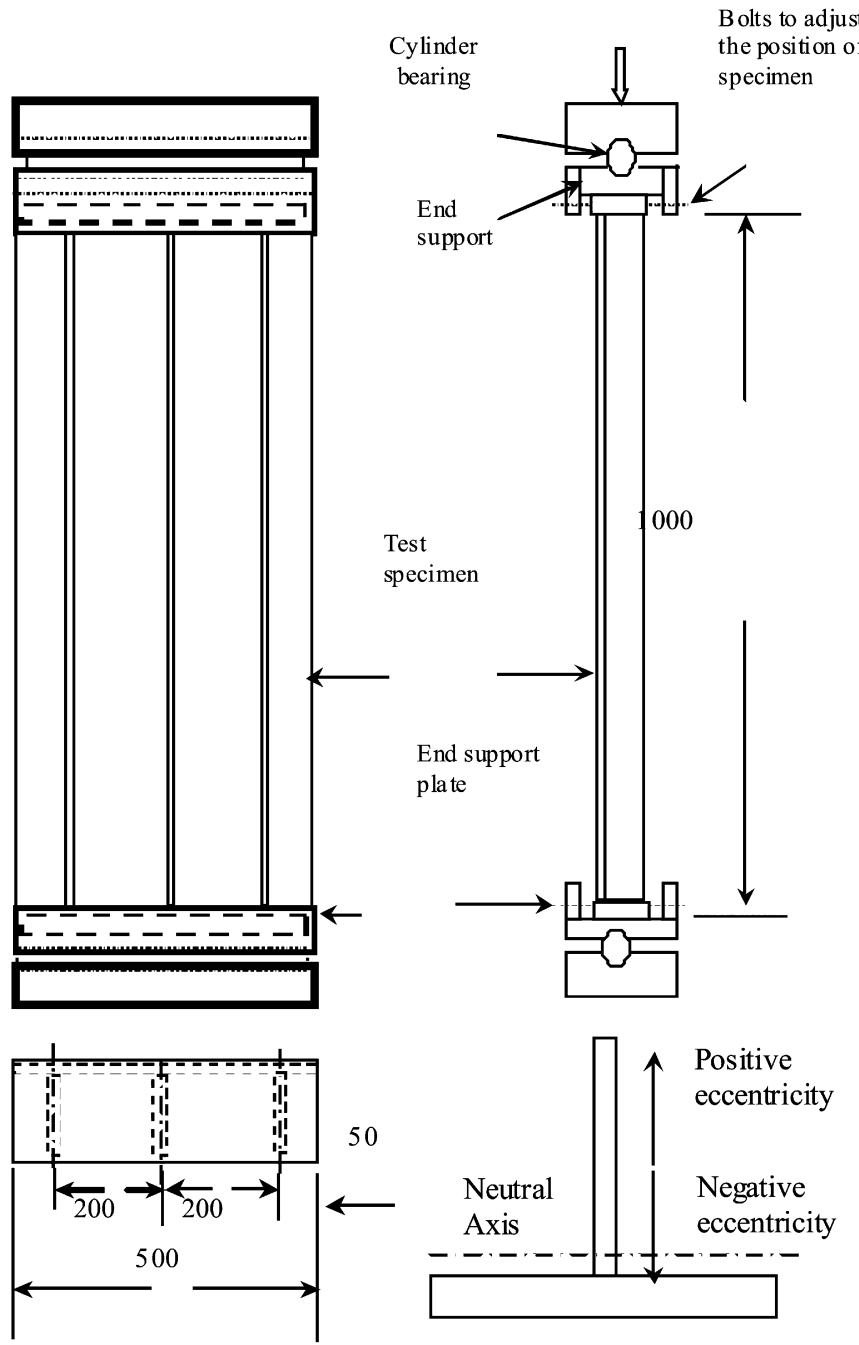

Fig. 6. Test rig set up with test specimen used by Zha and Moan [17].

was measured. The simply supported boundary conditions were provided by a steel cylinder bearing, with a diameter of $30 \mathrm{~mm}$ as shown in Fig. 6. More details are given in the paper of Zha and Moan [17].

The test specimens of Zha and Moan were designed to collapse by torsional buckling of the stiffeners. However, torsional buckling of the stiffeners interacted with local panel buckling of the plates, as observed from the test specimens with thin plate thickness. Significant torsional deformation of the stiffeners was observed when the axial compressive load was increased beyond $70 \%$ of ultimate load. The number of half waves in the collapse modes was influenced by the initial imperfection of the stiffeners. Because all test specimens were fabricated with two aluminium alloys (AA5083-H116 and AA6082-T6), various thicknesses of panel and stiffeners and stiffeners height, the buckling and plastic collapse behaviour varied during the tests. Typical behaviour of the specimens was described by using specimens EA2, A7, A12 and A16 as examples. Among the test specimens of Zha and Moan [17], two specimens A7 and A16 were chosen for validation purposes.

In addition of performing tests, Zha and Moan also performed numerical simulations by ABAQUS. The same tests on the specimens A7 and A16 were simulated using ANSYS by the authors. Figs. 7 and 8 represent, respectively, the collapse modes of the specimens A7 and A16 as obtained from tests and numerical simulations. Also, load-end shortening curves for these two 


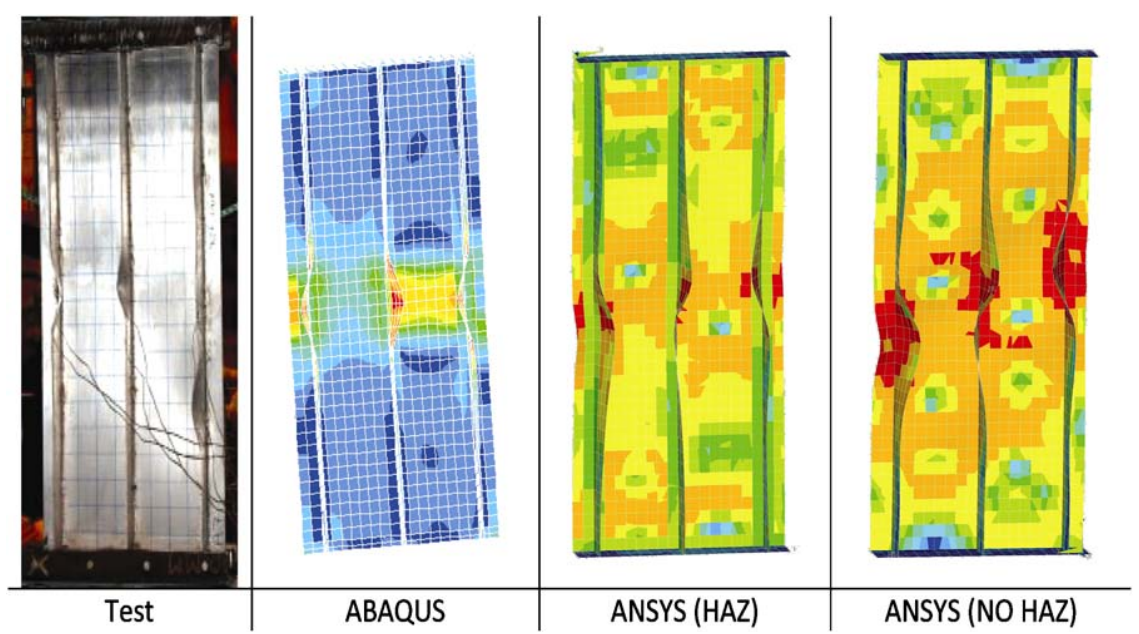

Fig. 7. Experimentally and numerically obtained collapse modes of the model A7 (material: AA5083-H116, Test and ABAQUS results considering HAZ are taken from Zha and Moan [17]. ANSYS results are obtained by authors).

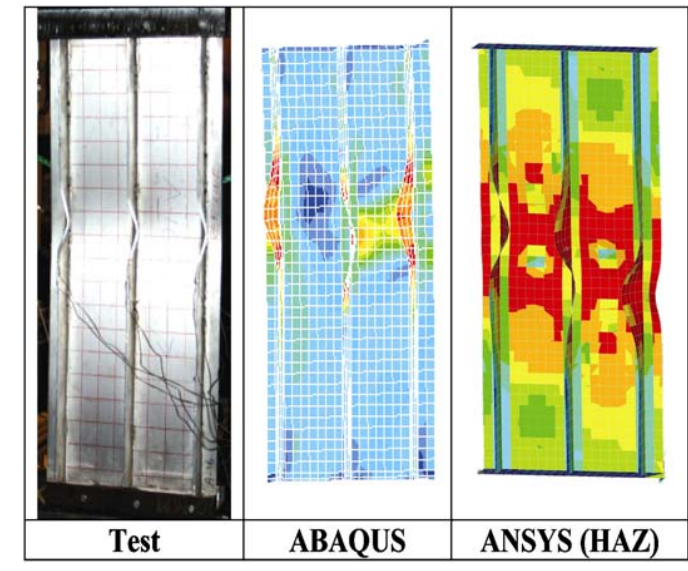

Fig. 8. Experimentally and numerically obtained collapse modes of the model A16 (material: AA6082-T6, Test and ABAQUS results considering HAZ are taken from Zha and Moan [17]. ANSYS results are obtained by authors).

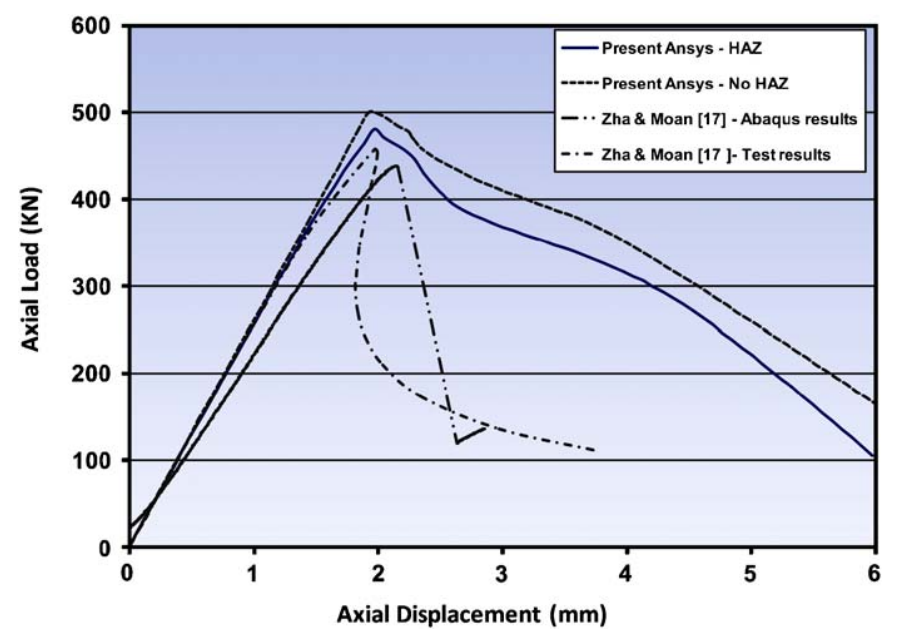

Fig. 9. Load-end shortening curves for the model A7.

specimens are shown in Figs. 9 and 10, respectively. As can be seen, when the heat-affected zone is not considered, the corresponding load-end shortening curves show an upper

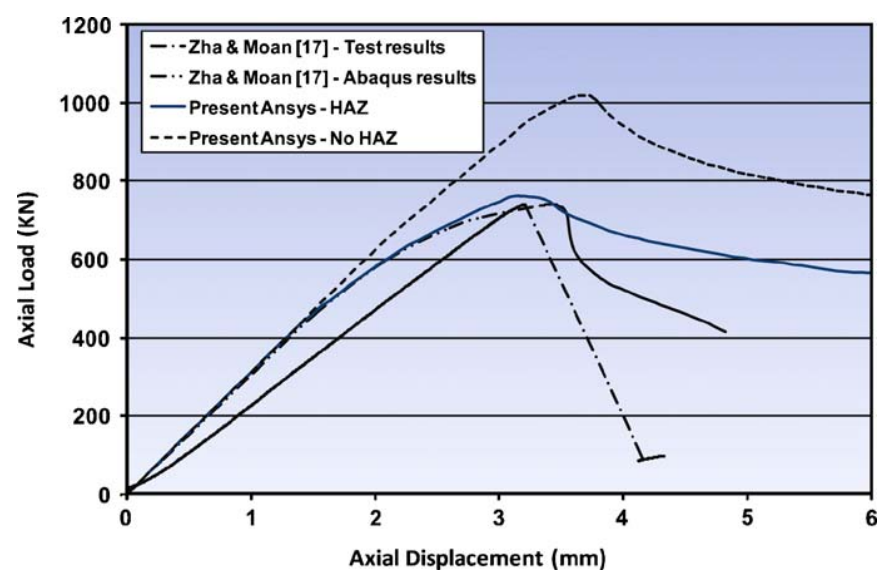

Fig. 10. Load-end shortening curves for the model A16.

ultimate strength than that obtained by tests. While considering heat-affected zone, the ultimate strength predicted by ABAQUS [17] and ANSYS differ, respectively, about 5\% and $8 \%$ from that obtained experimentally for the specimen A7. The difference between test and numerical results for the case of specimen A16 becomes much smaller when using either ABAQUS or ANSYS. More or less, the same collapse modes with similar features are obtained experimentally or numerically for both specimens A7 and A16, Figs. 7 and 8.

\section{Results and discussions}

\subsection{Elastic buckling strength}

A series of elastic large deflection analyses is performed on the continuous stiffened plate models subject to different levels of lateral pressure. The results are shown in Figs. 11-13 for the models of type 1, type 2 and type 3 , respectively. Horizontal axis of the curves in Figs. 11-13 represent the deflection at points A and $\mathrm{B}$ of the models, non-dimensionalised by plate thickness. Also in those figures, buckling strength of the models is non-dimensionalised by the elastic buckling strength of the unstiffened simply supported rectangular plates of the same size as the plate panels. Typical cross-sectional deformations of the models at the buckling modes are extracted and shown in Fig. 14. 
a

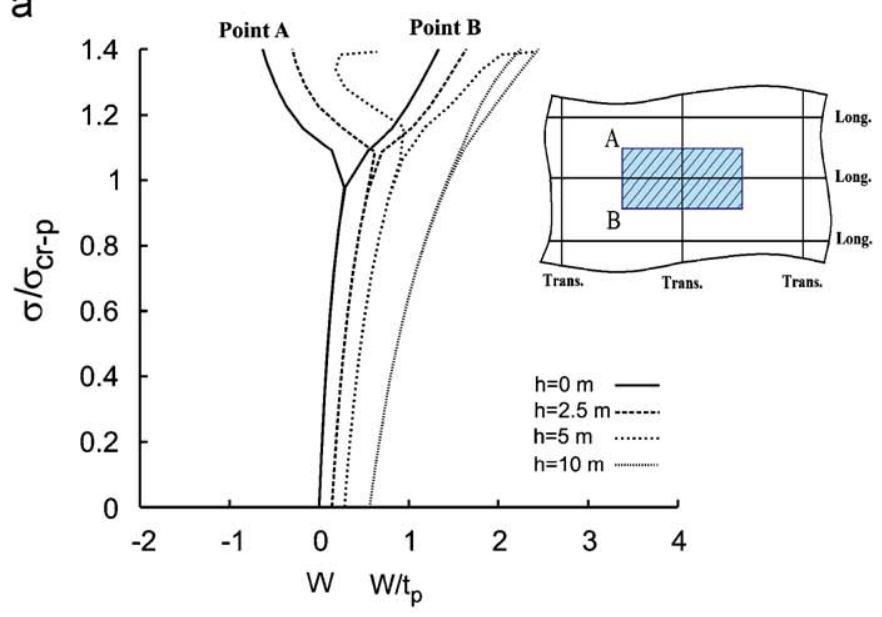

b

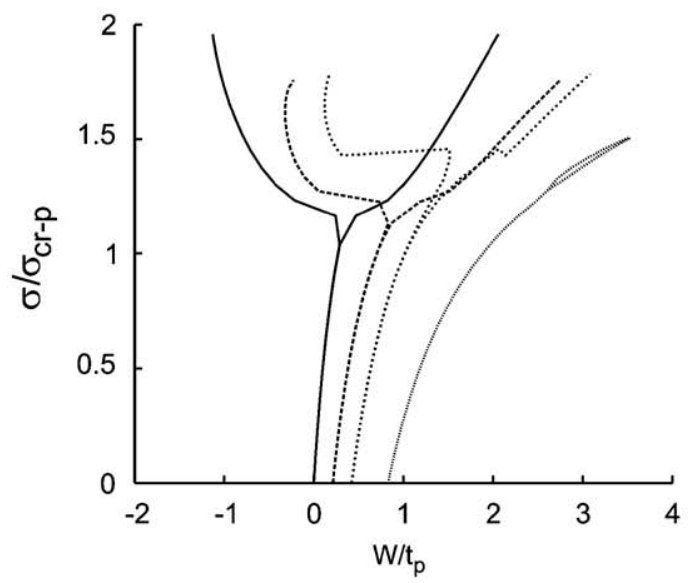

C

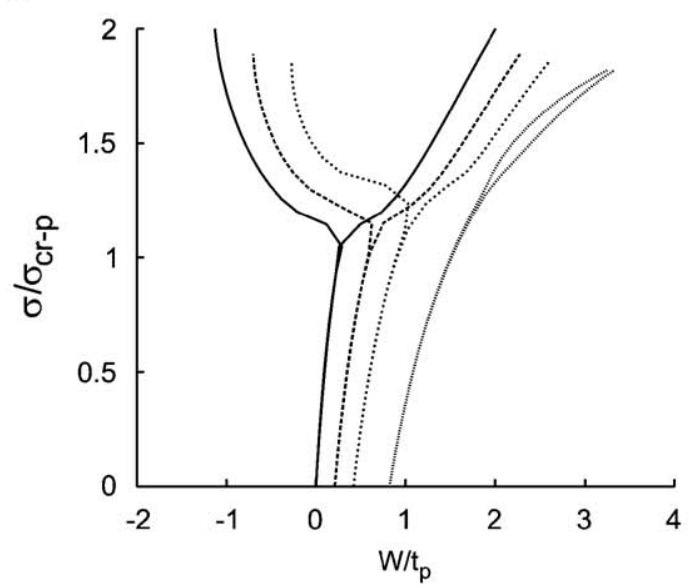

Fig. 11. Elastic bucking behaviour of the modes of type 1-week stiffener $(h=$ water head $(\mathrm{m})$ ). (a) Elastic buckling: type 1, flat bar. (b) Elastic buckling: type 1, angle bar and (c) Elastic buckling: type 1, tee bar.

A summary of the calculated elastic buckling strengths of the models are given in Table 2.

Elastic buckling of all models happen in a bifurcation way, Figs. 11-13. The greater the magnitude of lateral pressure, the higher the elastic bifurcation buckling strength. The initial deflection of the stiffened plate models is in a clamped mode. Applying lateral pressure on the models causes magnification of their clamped mode deflections. Subsequently, greater axial in- a

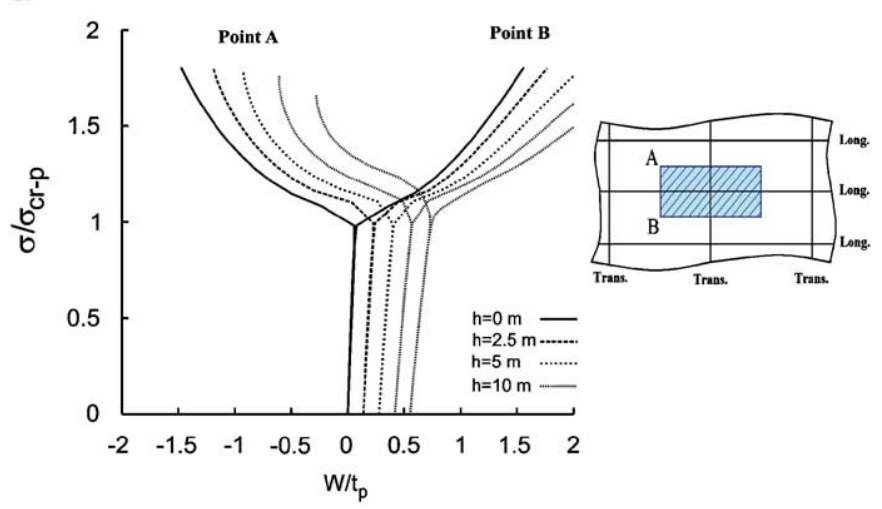

b

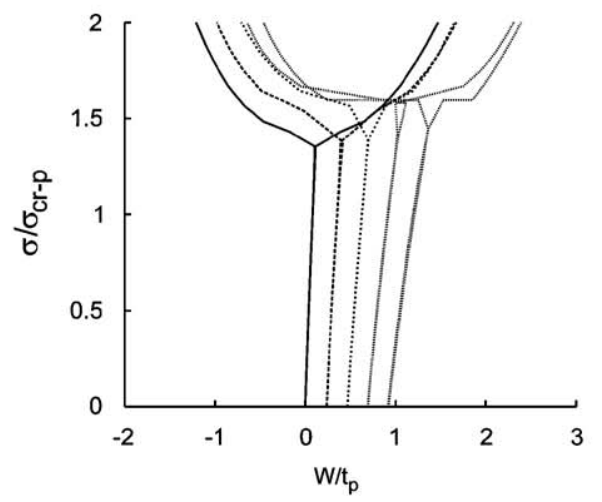

C

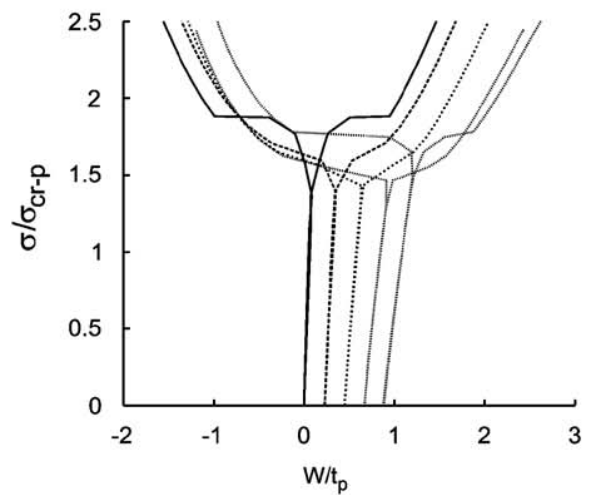

Fig. 12. Elastic bucking behaviour of the modes of type 2-medium stiffener $(h=$ water head $(\mathrm{m}))$. (a) Elastic buckling: type 2, flat bar. (b) Elastic buckling: type 2, angle bar and (c) Elastic buckling: type 2, tee bar.

plane compression is needed to change such a clamped mode deflection into a buckling mode. That is why the elastic buckling strength of the models increases with the increase in the lateral pressure loading on them.

The ratio of elastic buckling stress of any stiffened model to the buckling strength of un-supported simply supported plate $\left(\sigma_{c r} / \sigma_{c r-p}\right)$ shows the effects of stiffener on the buckling strength of the model. Flanged stiffeners as tee or angle shapes represent higher torsional rigidity for the stiffeners (Fig. 14) and as a result of this, elastic buckling strength increases when compared with that of the plate models stiffened with un-flanged flat-bar stiffeners (Table 2 and Figs. 11-13).

In some cases especially for F2 models, the ratio of $\sigma_{c r} / \sigma_{c r-p}$ falls below 1 . This means that the elastic buckling strength of such models under combined lateral pressure and in-plane compression is less than that of the un-stiffened plate mode under 
a

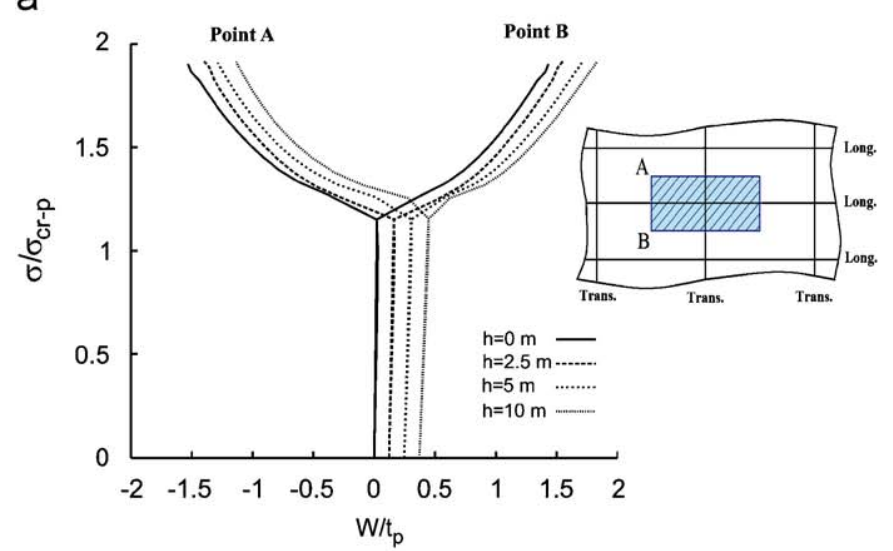

b

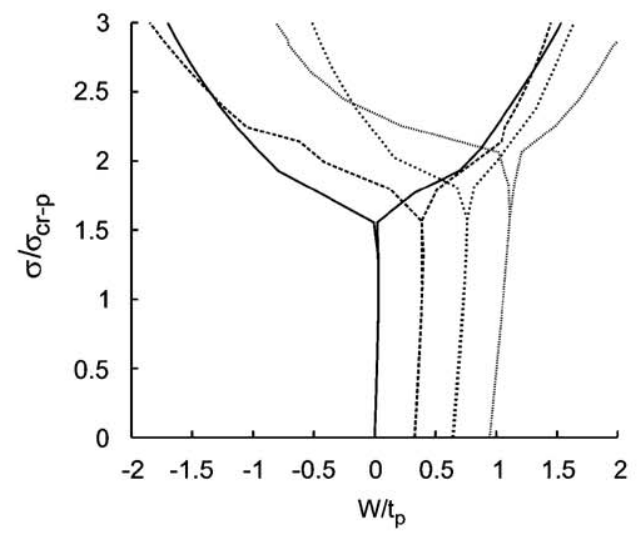

C

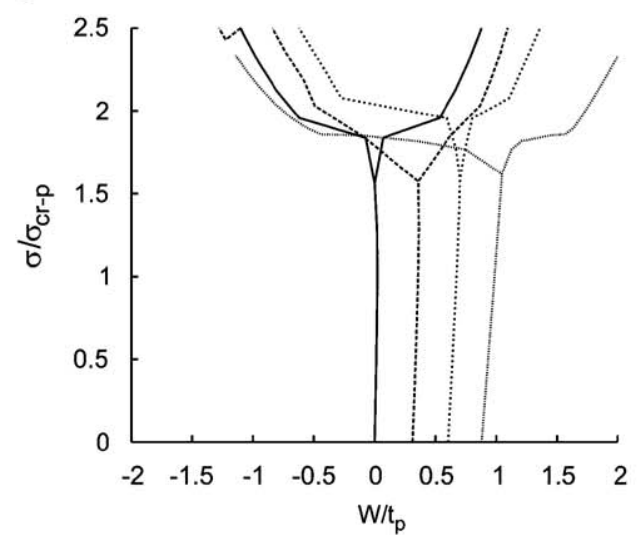

Fig. 13. Elastic bucking behaviour of the modes of type 3-heavy stiffener ( $h=$ water head $(\mathrm{m})$ ). (a) Elastic buckling: type 3, flat bar. (b) Elastic buckling: type 3, angle bar and (c) Elastic buckling: type 3, tee bar.

pure in-plane compression. The reason of this matter is due to the severe torsional deformation or tripping of flat-bar stiffeners.

\subsection{Ultimate strength and collapse behaviour}

A series of elastic-plastic large deflection analyses is performed on all models described earlier. Average stress-average strain relationships for all types of stiffened plates under combined longitudinal compression and lateral pressure are shown in Figs. 15-17. For a better understanding of the curves, numerical values of the ultimate strength of stiffened plates under combined longitudinal compression and lateral pressure are summarised in Table 3. Besides, collapse modes at ultimate

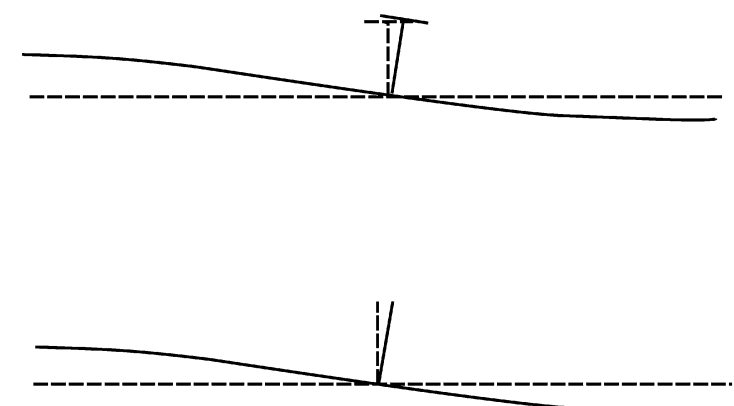

Z

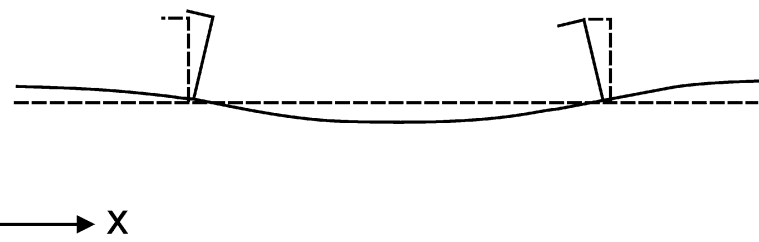

Fig. 14. Typical cross-sectional deformations at the buckling mode for the models of type 2-medium stiffener.

Table 2

Summary of buckling strength results for aluminium-stiffened plate models.

\begin{tabular}{|c|c|c|c|c|c|}
\hline \multirow[t]{2}{*}{ Water head $(\mathrm{m})$} & \multicolumn{5}{|c|}{ Type 1: weak stiffener } \\
\hline & 0 & \multicolumn{2}{|c|}{2.5} & 5 & 10 \\
\hline Model & $\sigma_{c r} / \sigma_{c r-}$ & & & & \\
\hline F1-flat stiff. & 1.0182 & & & 1.0858 & 1.0981 \\
\hline T1-tee stiff. & 1.0482 & & & 1.2367 & 1.2746 \\
\hline L1-angle stiff. & 1.0351 & & & 1.2334 & 1.2793 \\
\hline \multirow[t]{2}{*}{ Water head $(\mathrm{m})$} & \multicolumn{5}{|c|}{ Type 2: medium stiffener } \\
\hline & 0 & 5 & 10 & 15 & 20 \\
\hline Model & $\sigma_{c r} / \sigma_{c r-p}$ & & & & \\
\hline F2-flat stiff. & 0.9807 & 0.9856 & 0.9896 & 0.9915 & 0.9928 \\
\hline T2-tee stiff. & 1.3644 & 1.3933 & 1.4225 & 1.4649 & 1.4940 \\
\hline L2-angle stiff. & 1.3514 & 1.3780 & 1.3915 & 1.4165 & 1.4487 \\
\hline \multirow[t]{2}{*}{ Water head $(\mathrm{m})$} & \multicolumn{5}{|c|}{ Type 3: heavy stiffener } \\
\hline & 0 & 1 & & 20 & 30 \\
\hline Model & \multicolumn{5}{|c|}{$\sigma_{c r} / \sigma_{c r-p}$} \\
\hline F3-flat stiff. & \multicolumn{2}{|c|}{1.1517} & 1.1521 & 1.1538 & 1.1555 \\
\hline T3-tee stiff. & \multicolumn{2}{|l|}{1.5613} & 1.5730 & 1.5904 & 1.6179 \\
\hline L3-angle stiff. & \multicolumn{2}{|l|}{1.5550} & 1.5650 & 1.5752 & 1.5887 \\
\hline
\end{tabular}

strength level and at the final stage of calculations for some typical models under combined axial compression and different levels of lateral pressure are shown in Table 4. In what follows, description of the results and more details are presented.

\subsubsection{Stiffened plates of type 1}

For stiffened plates of type 1 with lower bending rigidity, the collapse mode occurs in a buckling mode under pure in-plane compression or with a low level of lateral pressure, Fig. 18. With the increase in the lateral pressure, collapse mode changes from the buckling mode to a "clamped mode", Fig. 18. Plates stiffened 
a

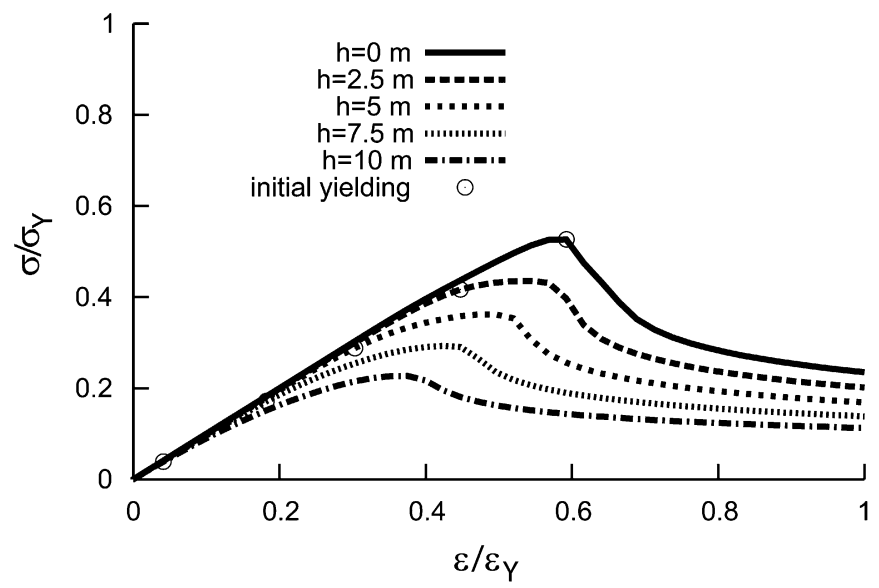

b

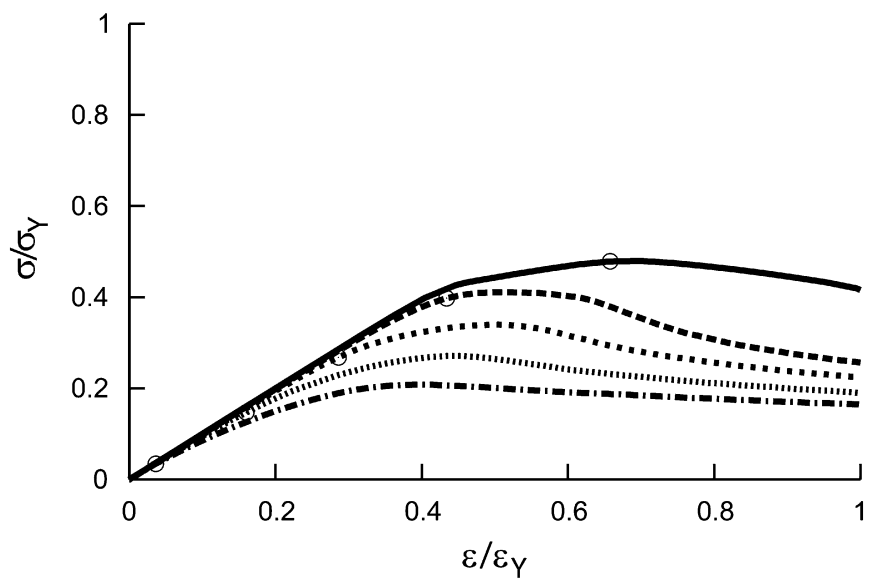

C

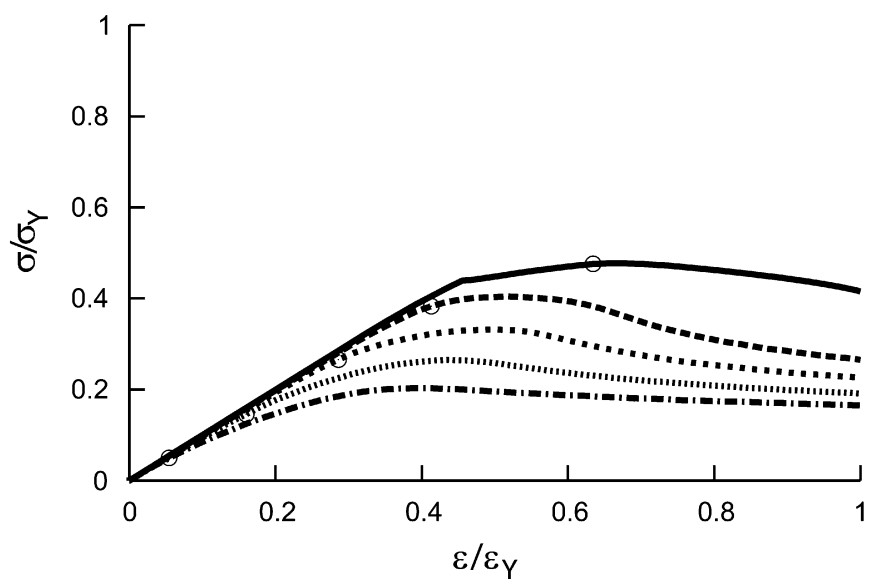

Fig. 15. Average stress-average strain relationships for aluminium-stiffened plates of type 1-week stiffener $(h=$ water head $(\mathrm{m}))$. (a) Stiffener: flat bar, type 1 . (b) Stiffener: tee bar, type 1 and (c) Stiffener: angle bar, type 1.

with either $\mathrm{T}$ (tee bar) or $\mathrm{L}$ (angle bar) stiffeners exhibit almost the same average stress-average strain behaviour, but those stiffened with $\mathrm{F}$ (flat bar) stiffeners have a relatively large amount of load shedding in the post-ultimate region (Fig. 15). With the increase in the applied lateral pressure, the ultimate compressive strength of the models decreases, Fig. 15 and Table 3. This is due to the fact that yielding starts sooner in the models as the lateral load increases. Subsequently, plasticity spreads in the models and its ultimate strength is attained earlier. a

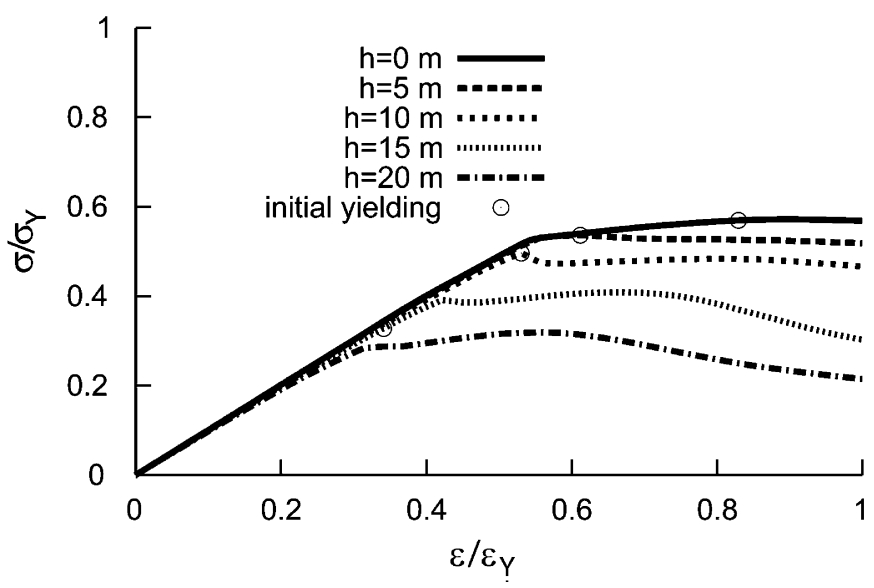

b

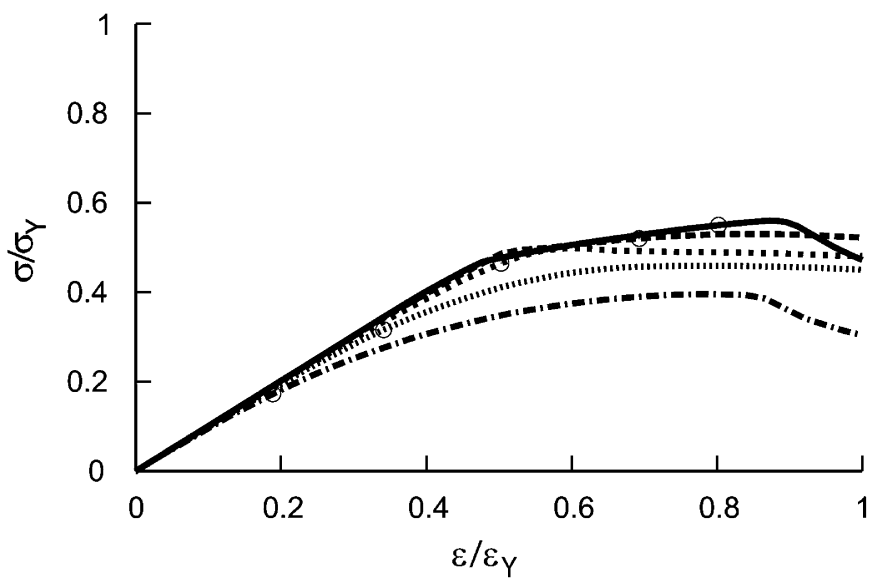

C

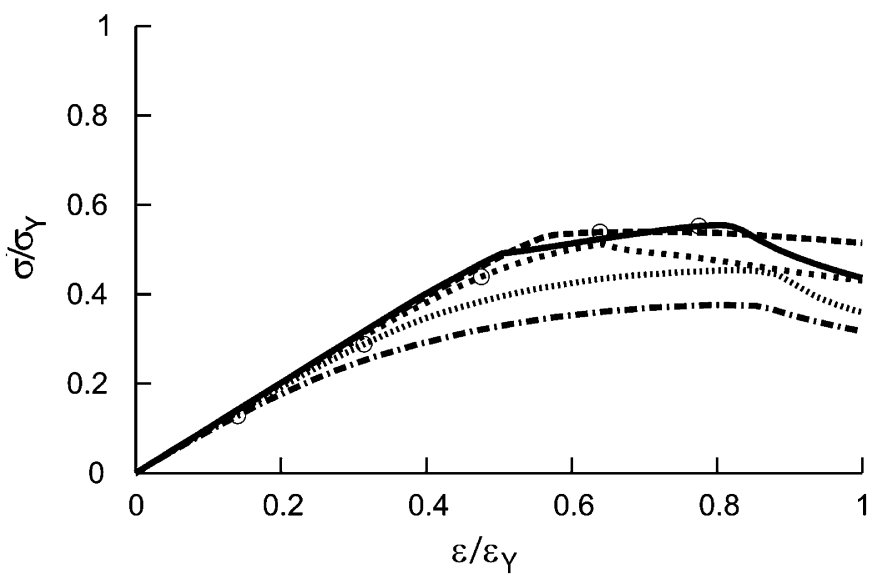

Fig. 16. Average stress-average strain relationships for aluminium-stiffened plates of type 2-medium stiffener $(h=$ water head $(\mathrm{m}))$. (a) Stiffener: flat bar, type 2. (b) Stiffener: tee bar, type 2 and (c) Stiffener: angle bar, type 2 .

\subsubsection{Stiffened plates of type 2}

Stiffened plates of type 2 have generally higher rigidities than those of type 1 . Those stiffened plates of type 2 that have flat-bar (F) stiffeners result in increasing post-ultimate strength, Fig. 16. Similar collapse behaviours to those explained for stiffened plates of type 1 again exists here among the results of plates with either $\mathrm{T}$ or L stiffeners, Fig. 16. Buckling strength as well as ultimate strength and strain of stiffened plates of this type are greater than those of the type 1, Figs. 15 and 16. In general, the same collapse 
a

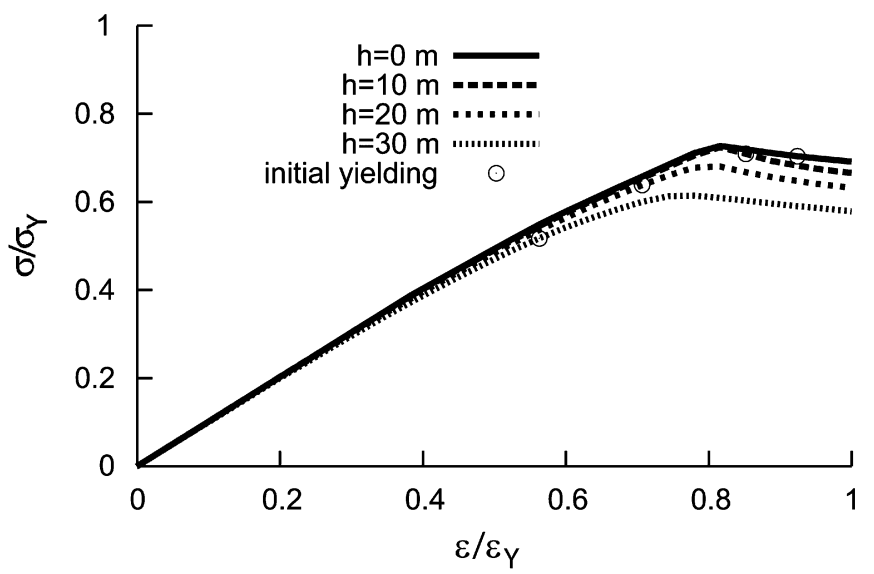

b

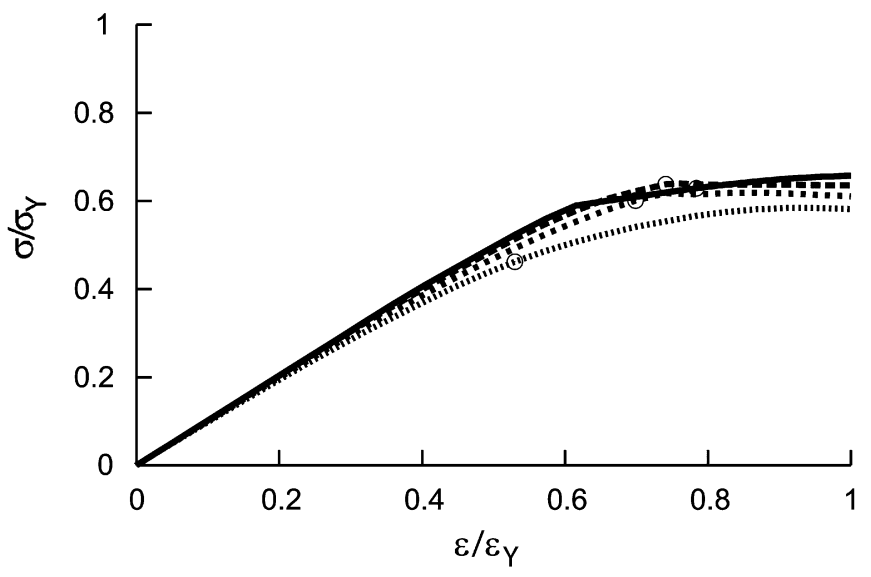

C

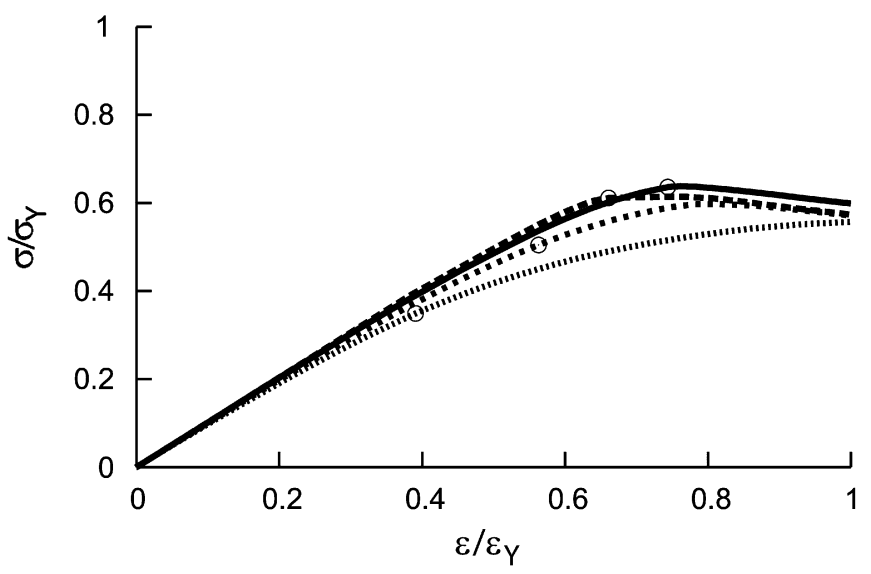

Fig. 17. Average stress-average strain relationships for aluminium-stiffened plates of type 3-heavy stiffener $(h=$ water head $(\mathrm{m}))$. (a) Stiffener: flat bar, type 3. (b) Stiffener: tee bar, type 3 and (c) Stiffener: angle bar, type 3.

behaviour is observed among the plotted results, Table 4 . The creation of the plastic hinges at the junction of the stiffened plate with transversal ones is a common feature of the collapse mode at relatively high lateral loads, regardless of the type and stiffener geometry.

\subsubsection{Stiffened plates of type 3}

The stiffened plates of this type have the highest value of the bending rigidity and lowest value of column slenderness
Table 3

Summary of ultimate strength results for aluminium-stiffened plates.

\begin{tabular}{|c|c|c|c|c|c|}
\hline \multirow[t]{2}{*}{ Water head $(\mathrm{m})$} & \multicolumn{5}{|c|}{ Type 1: weak stiffener } \\
\hline & 0 & 2.5 & 5 & 7.5 & 10 \\
\hline Model & $\sigma_{U l t} / \sigma_{Y}$ & & & & \\
\hline F1-flat stiff. & 0.5263 & 0.4352 & 0.3617 & 0.2931 & 0.2270 \\
\hline T1-tee stiff. & 0.4797 & 0.4111 & 0.3395 & 0.2709 & 0.2079 \\
\hline L1-angle stiff. & 0.4770 & 0.403 & 0.3324 & 0.2647 & 0.2028 \\
\hline \multirow[t]{2}{*}{ Water head $(\mathrm{m})$} & \multicolumn{5}{|c|}{ Type 2: medium stiffener } \\
\hline & 0 & 5 & 10 & 15 & 20 \\
\hline Model & $\sigma_{U I t} / \sigma_{Y}$ & & & & \\
\hline F2-flat stiff. & 0.5716 & 0.5363 & 0.4956 & 0.4088 & 0.3190 \\
\hline T2-tee stiff. & 0.5597 & 0.5304 & 0.4987 & 0.4589 & 0.3956 \\
\hline L2-angle stiff. & 0.5550 & 0.5396 & 0.5115 & 0.4536 & 0.3762 \\
\hline \multirow[t]{2}{*}{ Water head (m) } & \multicolumn{5}{|c|}{ Type 3: heavy stiffener } \\
\hline & 0 & 10 & & 20 & 30 \\
\hline Model & \multicolumn{5}{|l|}{$\sigma_{U l t} / \sigma_{Y}$} \\
\hline F3-flat stiff. & 0.7265 & \multicolumn{2}{|c|}{0.7236} & 0.6800 & 0.6142 \\
\hline T3-tee stiff. & 0.6584 & \multicolumn{2}{|c|}{0.6399} & 0.6185 & 0.5843 \\
\hline L3-angle stiff. & 0.6139 & \multicolumn{2}{|c|}{0.6382} & 0.5973 & 0.5666 \\
\hline
\end{tabular}

parameter. It can be seen that the average stress-average strain curves follow similar trends, while the value of the ultimate strength increases (Fig. 17). Also the strength reserve after collapse is significant. At the final stage of calculations, it is observed that unloading (stress removal) takes place in some part of the stiffened plate while in the remaining parts localised plastic deformations are accumulated, Fig. 19. This behaviour is also significant in some other cases in stiffened plates of types 1 and 2 .

For those welded aluminium plates of this type that are stiffened with flat bars, tripping failure of stiffeners is expected to occur in their mid-spans. This phenomenon is not so pronounced in these cases in the present study due to their special geometric characteristics. Besides, severe tripping of longitudinal stiffeners is observed at the line of transverse supporting members.

\subsection{Sensitivity analysis on the ultimate strength}

In this study, the fabrication-induced initial imperfections were produced in the same way as that applied by Rigo et al. [19] in their extensive sensitivity study on stiffened aluminium plate panels under pure in-plane longitudinal compression. In order to cover a wide range of probable cases for fabricationinduced initial imperfections, HAZ characteristics, maximum magnitude of initial deflection and also welding residual stresses were changed in a systematic way and their effects on the ultimate strength and collapse behaviour of stiffened plates were investigated in details. The results were reported in Sections 3.3.1 and 3.3.2.

\subsubsection{Width of $H A Z$}

Sensitivity of the ultimate strength of the stiffened plate models to the width of HAZ has been studied in this investigation. The results for sensitivity analysis regarding width of the HAZ is summarised in Fig. 20 as a typical case for models of type 2. The results show that with the increase in the HAZ width in the plate, there is a decrease in the ultimate strength of the stiffened plate in the bilinear trend regardless of the value of lateral load. In the first 
Table 4

Collapse modes at ultimate strength level (left column) and at the final stage of calculations (right column) for some typical models.

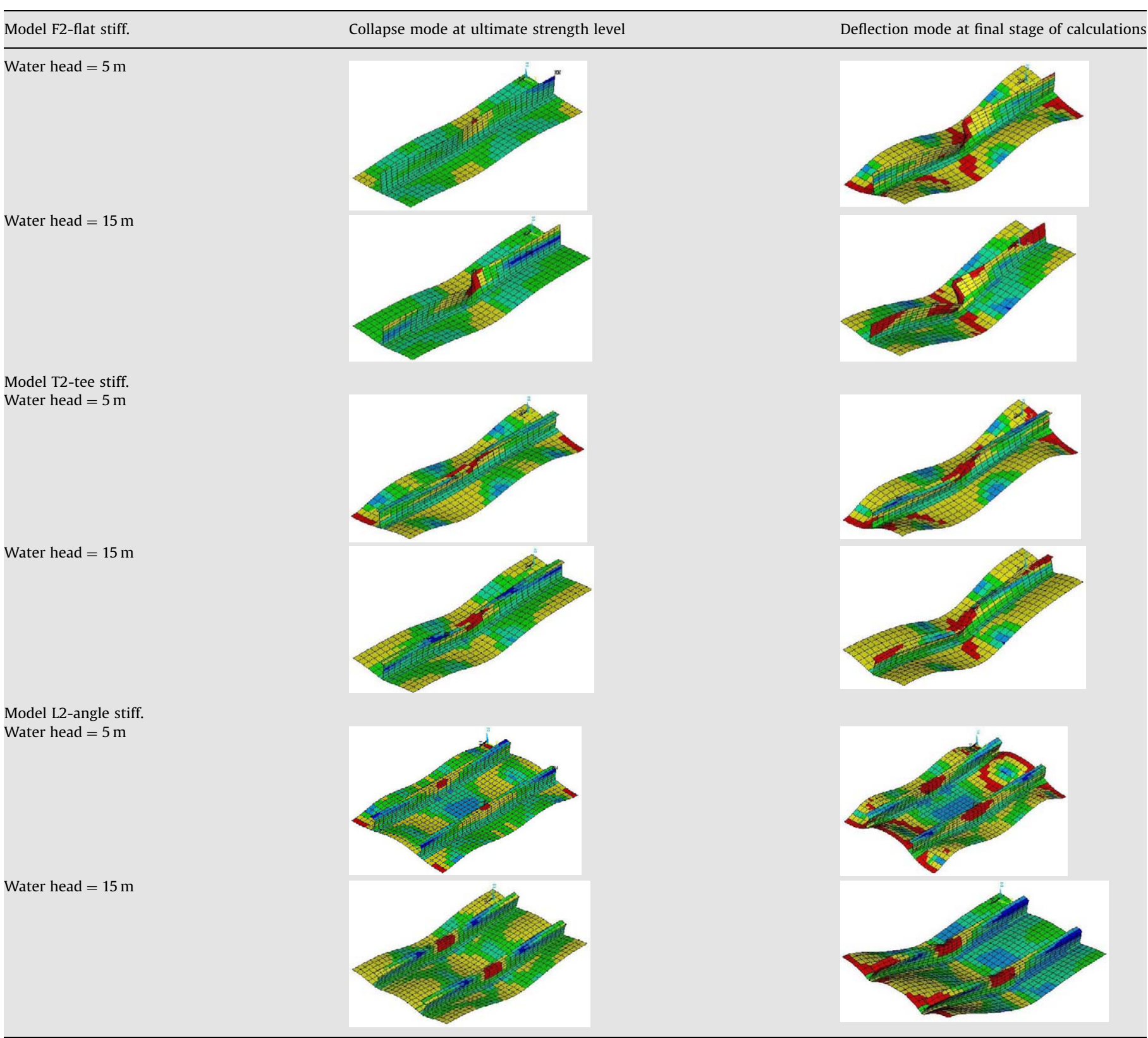

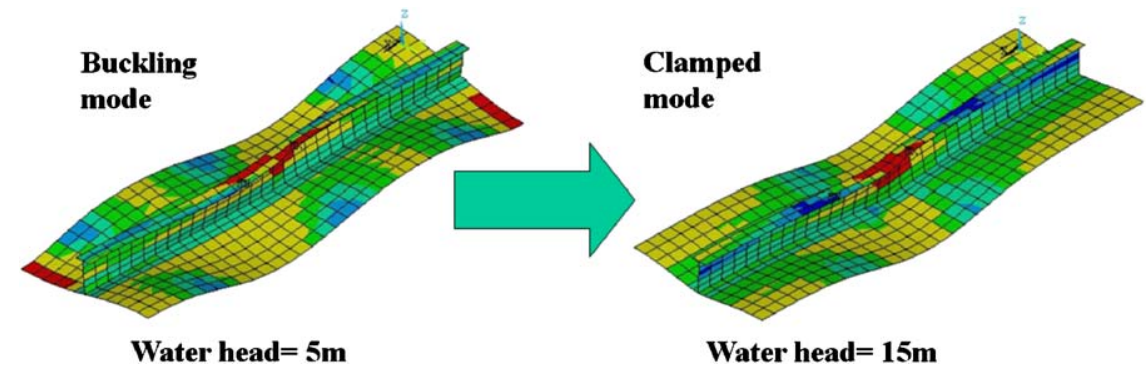

Water head $=5 \mathbf{m}$

Water head $=15 \mathrm{~m}$

Fig. 18. Change of buckling collapse mode to clamped collapse mode in $\mathrm{T} 2$ model.

$25 \mathrm{~mm}$, the average reduction is about $9.88 \%$, while in the second and third $25 \mathrm{~mm}$, this reduction is about an average of $6.33 \%$ and $5.18 \%$, respectively. Almost similar trends are observed for the other types. Thus their curves are not produced here.

\subsubsection{Welding residual stresses}

Also the effect of the welding residual stresses on the ultimate strength of stiffened plate models has been investigated. It was assumed that across the HAZ width of $25 \mathrm{~mm}$, the tensile residual 


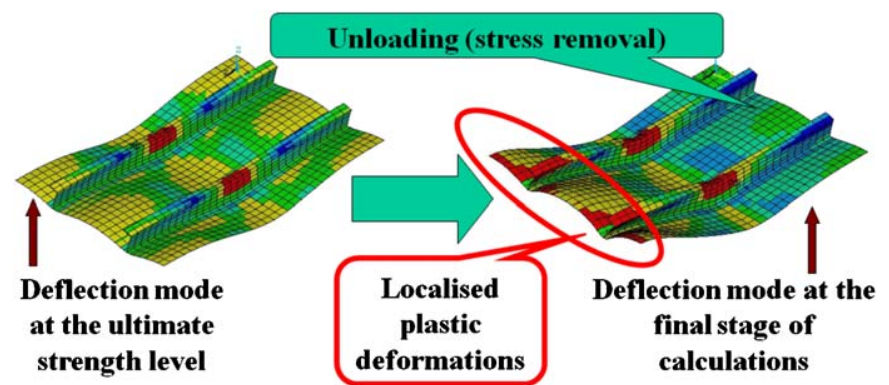

Fig. 19. Unloading and localised plastic deformations in L2 model.

a

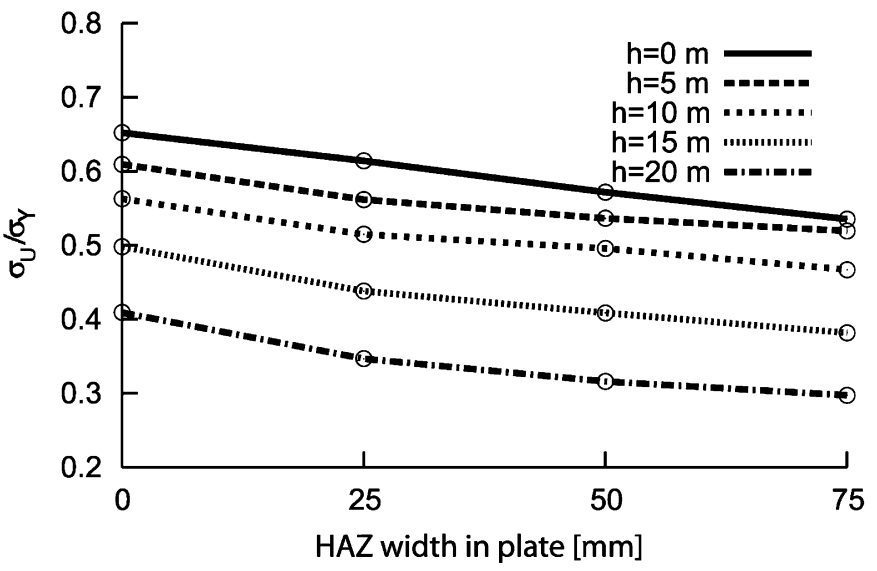

b

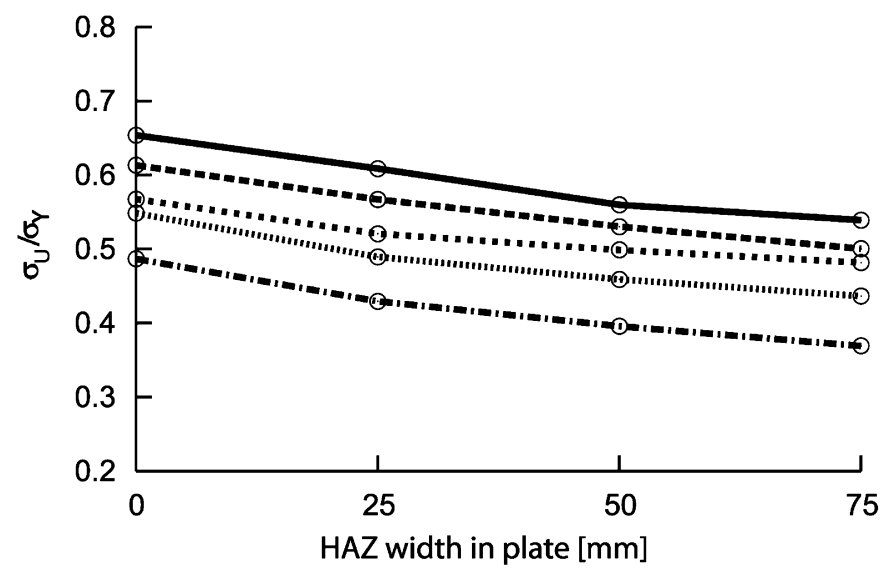

C

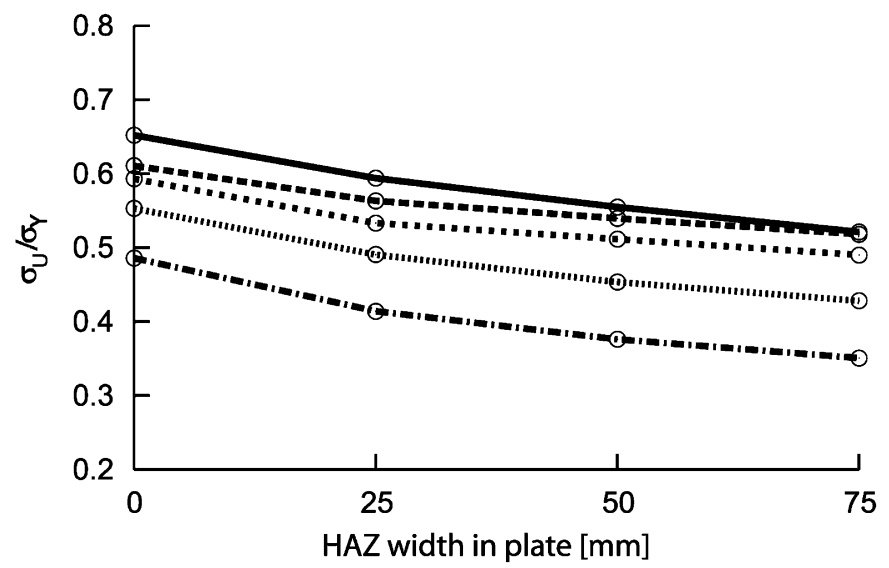

Fig. 20. Sensitivity of the ultimate strengths for aluminium-stiffened plates of type 2 under combined axial compression and different levels of lateral pressure versus different HAZ width. (a) Stiffener: flat bar, type 2. (b) Stiffener: tee bar, type 2 and (c) Stiffener: angle bar, type 2 .
Table 5

Some results on the effect of welding residual stresses on the ultimate strength of aluminium-stiffened plates.

\begin{tabular}{lccccc}
\hline Water head (m) & \multicolumn{5}{l}{ Type 2: medim stiffener-with residual stress } \\
\cline { 2 - 6 } & 0 & 5 & 10 & 15 & 20 \\
\hline$\sigma_{\text {Ult }} / \sigma_{Y}$ & & & & & \\
F2-flat stiff. & 0.5694 & 0.5183 & 0.4868 & 0.4068 & 0.3149 \\
T2-tee stiff. & 0.5474 & 0.4983 & 0.4252 & 0.3836 & 0.3185 \\
L2-angle stiff. & 0.5487 & 0.4878 & 0.4676 & 0.4058 & 0.3363 \\
Percentage of difference with & reference (without residual stress) & \\
F2-flat stiff. & -0.38 & -3.36 & -1.78 & -0.49 & -1.29 \\
T2-tee stiff. & -2.20 & -6.05 & -14.74 & -16.41 & -19.49 \\
L2-angle stiff. & -1.14 & -9.60 & -8.58 & -10.54 & -10.61 \\
\hline
\end{tabular}

stresses equal to the yield stress of the HAZ material exists. Besides, the compressive welding residual stresses outside the HAZ width was considered to be of uniform distribution. A part of the obtained results has been summarised in Table 5 . As it can be seen, with increase in the magnitude of lateral pressure, the reduction in the ultimate strength of the models is increased. The reduction of the ultimate strength for plates stiffened with flat bar is between $(0.3-3.3 \%)$, while lateral pressure head increases from zero to $20 \mathrm{~m}$. This reduction in case of plates stiffened with $\mathrm{L}$ and $\mathrm{T}$ stiffeners lie, respectively, in the range (1.1-10.6\%) and (2.2-19.5\%).

\subsubsection{Maximum magnitude of initial deflections}

The effects of the maximum magnitude of initial deflection on the ultimate strength of the models under different levels of lateral pressure are also investigated. An extract of the results, for the stiffened plate models of type 2, is shown in Fig. 21. As it can be seen, in any level of lateral pressure, changing the maximum magnitude of initial deflection has a very slight effect on the ultimate strength of the stiffened plate models. In fact, the reduction in the ultimate strength of stiffened plates has a linear trend with the increase in the maximum magnitude of initial deflection. Change in the maximum magnitude of initial deflection has more diminishing effect on the ultimate strength of plates stiffened with flat-bar stiffeners. In this case, the ultimate strength is approximately decreased about $1.8 \%$ instead of $1 \mathrm{~mm}$ increase in the maximum magnitude of initial deflection. The amount of decrease in the ultimate strength of stiffened aluminium plate with angle-bar and tee-bar stiffeners is, respectively, about $1.3 \%$ and $1.0 \%$.

\section{Conclusions}

Post-buckling behaviour of high-strength aluminium alloy stiffened plates subjected to combined axial compression load and different magnitudes of lateral pressure using non-linear finite element approach was investigated. Both material and geometric non-linearities were taken into account. The principal variables studied were the plate thickness, boundary conditions and the stiffener geometries beside the geometrical imperfection, the width of the welding HAZ and welding residual stresses. The influence of these variables on the post-buckling behaviour and ultimate strength of such stiffened plates was investigated in details. The main draw-backs are:

- It was seen that for small values or levels of lateral pressure, the stiffened plate collapses under axial in-plane compression in a simply supported mode. 
a

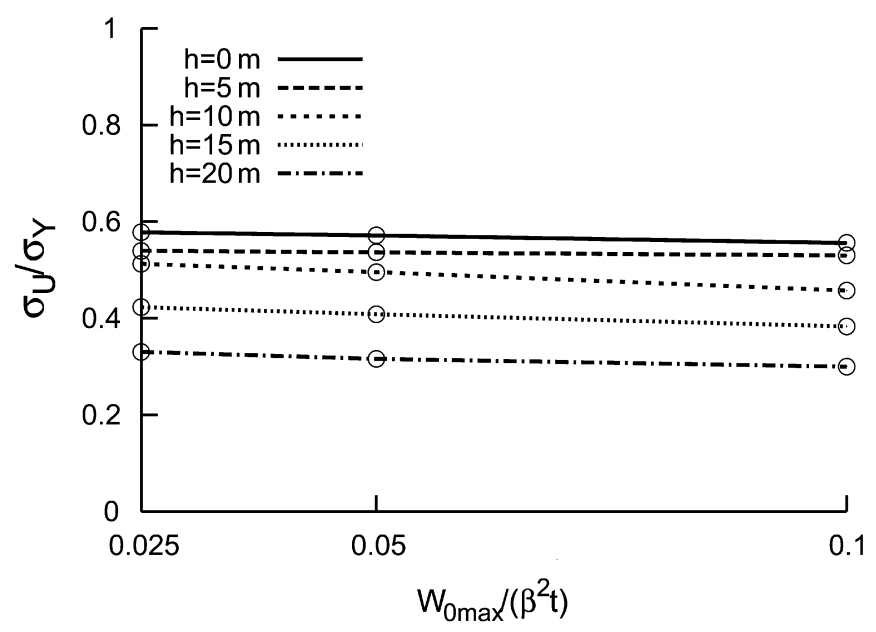

b

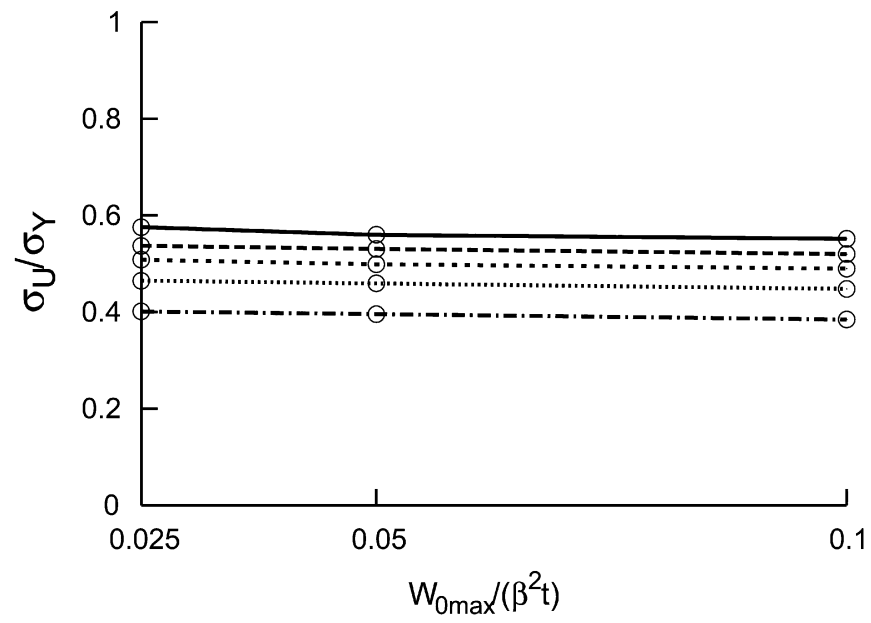

C

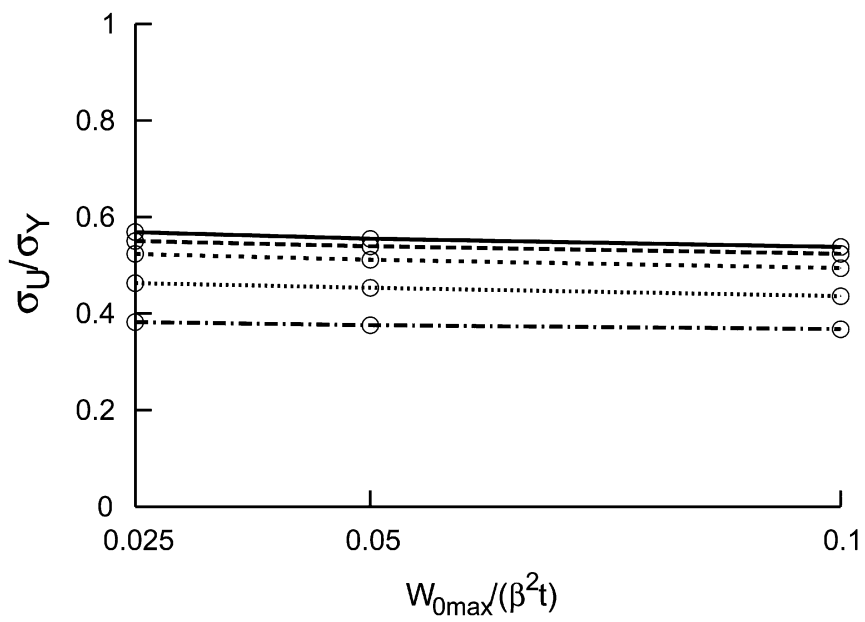

Fig. 21. Sensitivity of the ultimate strengths for aluminium-stiffened plates of type 2 under combined axial compression and different levels of lateral pressure versus different maximum magnitudes of initial deflection. (a) Stiffener: flat bar, type 2 . (b) Stiffener: tee bar, type 2 and (c) Stiffener: angle bar, type 2.

- With increase in the applied lateral pressure, collapse mode changes to a clamped mode.

- With increase in the HAZ width in the plate, the ultimate strength of the stiffened plate decreases in a bilinear trend regardless of the value of lateral load.
- Welding residual stresses lead to the reduction in the ultimate capacity of the stiffened plates. The amount of reduction is a function of both the type of stiffener and also the value of lateral pressure.

- Maximum magnitude of initial deflection has a very slight amount of effect on the ultimate strength of stiffened aluminium plates.

\section{References}

[1] Murray NW. Buckling of stiffened panels loaded axially and in bending. Struct Eng 1973;51(8):285-301.

[2] Dorman AP, Dwight JB. Tests on stiffened compression panels and plate panels. In: Proceedings of the international conference on steel box girder bridges, February. London: The Institution of Civil Engineers; 1973. p. 63-75.

[3] Smith CS. Compressive strength of welded steel ship grillages. Trans R Inst Nav Archit 1975; 117:325-47.

[4] Dow RS. Testing and analysis of a 1/3-scale welded steel frigate model. In: Smith CS, Dow RS, editors. Advances in marine structures-2. Amsterdam: Elsevier; 1991.

[5] Ghavami K. Experimental study of stiffened plates in compression up to collapse. J Constr Steel Res 1994;28(2):197-222 [Special Brazilian Issue, Gues Editor Khosrow Ghavami].

[6] Sherbourne AN, Liaw CY, Marsh C. Stiffened plates in uniaxial compression. IABSE 1971;31:145.

[7] Moolani FM, Dowling PJ. Ultimate load behaviour of stiffened plates in compression. Steel Plates Structures. In: Dowling PJ, Harding JE, Frieze PA editors., Proceedings of the International Conference on Steel Plated Structures, Imperial College, London, July 1976. Crosby Lockwood Staples, p. 51-88.

[8] Guedes Soares C, Soreide TH. Behaviour and design of stiffened plates under predominantly compressive loads. Int Shipbuild Prog 1983;341.

[9] Bonello MA, Chryssanthopoulos MK, Dowling PJ. Ultimate strength design of stiffened plates under axial compression and bending. Mar Struct 1993;6: 533-52.

[10] Chen Q, Zimmerman TJE, DeGeer D, Kennedy, BW. Strength and stability testing of stiffened plate components. Ship Structural Committee Report SSC399, 1997.

[11] Clarke JD, Narayanan R. Buckling of aluminium alloy stiffened plate ship structure. In: Proceedings of the international conference on steel and aluminium structures, Cardiff, July 1987; aluminium structures-advances design and construction. Amsterdam: Elsevier; 1987. p. 81-92.

[12] Aalberg A, Langseth M, Larsen PK. Stiffened aluminium panels subjected to axial compression. Thin Walled Struct 2001;39:861-85.

[13] Aalberg A, Langseth M, Malo KA. Ultimate strength of stiffened aluminium plates. Norwegian University of Science and Technology, Department of Structural Engineering 1998.

[14] Kristensen QHH, Moan T. Ultimate strength of aluminium plates under biaxia loading. In: Proceedings of the fifth international conference on fast sea transportation. New York, 1999.

[15] Zha Y, Moan T, Hanken E. Experimental and numerical study of torsional buckling of stiffeners in aluminium panels. In: Proceedings of the fifth international conference on ISOPE, Seattle, May 2000. p. 249-55.

[16] Zha Y, Moan T, Hanken E. Ultimate strength of stiffened aluminium panels with predominantly torsional failure modes. Thin-Walled Struct 2001;39: 631-48.

[17] Zha Y, Moan T. Experimental and numerical prediction of collapse of flat bar stiffeners in aluminium panels. J Struct Eng 2003;129(2):160-8.

[18] Hopperstad OS, Langseth M, Hanssen L. Ultimate compressive strength of plate elements in aluminium: correlation of finite element analyses and tests. Thin-Walled Struct 1998;29:31-46.

[19] Rigo P, et al. Sensitivity analysis on ultimate strength of aluminium stiffened panels. Marine Struct 2003;16:437-68.

[20] Paik JK, et al. Ultimate limit state design technology for aluminum multi-hull ship structures. Trans SNAME 2005;113:270-305.

[21] Paik JK, et al. The statistics of weld induced initial imperfections in aluminum stiffened plate structures for marine applications. Int J Maritime Eng 2006;148(4):19-63.

[22] Collette MD. The impact of fusion welds on the ultimate strength of aluminum structures. In: Proceedings of PRADS 2007/ Houston, USA.

[23] Paik JK. Empirical formulations for predicting the ultimate compressive strength of welded aluminum stiffened panels. Thin-Walled Struct 2007;45: $171-84$.

[24] Sielski RA. Research needs in aluminum structure. Ships Offshore Struct 2008:3(1):57-65.

[25] Paik JK, et al. Mechanical collapse testing on aluminum stiffened plate structures for marine applications. Mar Technol 2008;45(4):228-40.

[26] Paik JK, et al. Mechanical collapse testing on aluminum stiffened panels for marine applications. Ship Structure Committee Report, SSC-451 2008, Washington, D.C. (http://www.shipstructure.org). 
[27] Paik JK. Buckling collapse testing of friction stir welded aluminum stiffened plate structures, Ship Structure Committee Report SR-1454 2009, Washington, D.C. (http://www.shipstructure.org).

[28] ANSYS User's Manual (Version 7.1). Houston, Swanson Analysis Systems Inc. 2003.

[29] Yao T, Fujikubo M, Yanagihara D, Irisawa M. Consideration on FEM modelling for buckling/plastic collapse analysis of stiffened plates. Trans West-Jpn Soc Nav Arc 1998;85:121-8 [in Japanese].

[30] Fujikubo M, Yao T, Varghese B, Zha Y, Yamamura K. Elastic local buckling strength of stiffened plates considering plate/stiffener interaction and lateral pressure. In: Proc of eighth international offshore and polar engineering conference. Vol. IV. 1998, p. 292-9.

[31] Khedmati MR Ultimate strength of ship structural members and systems considering local pressure loads. Dr. Eng. Thesis, Graduate School of Engineering, Hiroshima University 2000.

[32] Smith CS, Davidson PC, Chapman JC, Dowling PJ. Strength and stiffness of ships' plating under in-plane compression and tension. Trans RINA 1987;129: 277-96.

[33] Varghese B. Buckling/plastic collapse strength of plates and stiffened plates under combined loads, Dr. Eng. Thesis, Hiroshima University 1998. 